\title{
Dynamical response of the Arctic atmospheric boundary layer process to uncertainties in sea-ice concentration
}

\author{
Hyodae Seo ${ }^{1}$ and Jiayan Yang ${ }^{1}$ \\ Received 3 June 2013; revised 30 October 2013; accepted 30 October 2013; published 20 November 2013.
}

[1] Impact of sea-ice concentration (SIC) on the Arctic atmospheric boundary layer (ABL) is investigated using a polar-optimized version of the Weather Research and Forecasting (Polar WRF) model forced with SIC conditions during three different years. We present a detailed comparison of the simulations with historical ship and ice station based data focusing on September. Our analysis shows that Polar WRF provides a reasonable representation of the observed $\mathrm{ABL}$ evolution provided that SIC uncertainties are small. Lower skill is obtained, however, with elevated SIC uncertainties associated with incorrect seasonal evolution of sea ice and misrepresentation of ice thickness near the marginal ice zone (MIZ). The result underscores the importance of accurate representation of ice conditions for skillful simulation of the Arctic ABL. Further, two dynamically distinctive effects of sea ice on the surface wind were found, which act on different spatial scales. Reduced SIC lowers ABL stability, thereby increasing surface-wind (W10) speeds. The spatial scale of this response is comparable to the basin scale of the SIC difference. In contrast, near-surface geostrophic wind $(\mathrm{Wg}$ ) shows a strong response in the MIZ, where a good spatial correspondence exists among the Laplacian of the sea level pressure (SLP), the surface-wind convergence, and the vertical motion within the ABL. This indicates that SIC affects Wg through variation in SLP but on a much narrower scale. Larger-amplitude and broader-scale response in W10 implies that surface-wind stress derived from Wg to drive ice-ocean models may not fully reflect the effect of SIC changes.

Citation: Seo, H., and J. Yang (2013), Dynamical response of the Arctic atmospheric boundary layer process to uncertainties in sea-ice concentration, J. Geophys. Res. Atmos., 118, 12,383-12,402, doi:10.1002/2013JD020312.

\section{Introduction}

[2] Sea-ice concentration (SIC) is a key factor for surface fluxes in the Arctic atmospheric boundary layer (ABL). Sea ice effectively insulates the cold lower atmosphere from a relatively warmer ocean by suppressing latent and sensible heat fluxes from the ocean. Variations in SIC affect the radiative fluxes and regulate surface air and skin temperatures and thus the stability of the ABL. The importance of sea ice for the Arctic and broader-scale climate system has long been recognized [e.g., Budyko, 1969; Manabe et al., 1992; Deser et al., 2004; Alexander et al., 2004; Budikova, 2009; Porter et al., 2012]. In a large-eddy simulation model by Lüpkes et al. [2008], for example, a 1\% variation in SIC resulting from opening leads can change the surface air temperature by $3.5 \mathrm{~K}$ in winter. Similarly, Ebner et al. [2011], using idealized mesoscale modeling, reported that anomalous air temperatures can reach up to $5 \mathrm{~K}$ over the Laptev Sea polynyas due to a more convective boundary layer and enhanced

\footnotetext{
${ }^{1}$ Physical Oceanography Department, Woods Hole Oceanographic Institution, Woods Hole, Massachusetts, USA

Corresponding author: H. Seo, Physical Oceanography Department, Woods Hole Oceanographic Institution, 266 Woods Hole Road, MS\#21, Woods Hole, MA 02543, USA. (hseo@whoi.edu)

(C)2013. American Geophysical Union. All Rights Reserved. 2169-897X/13/10.1002/2013JD020312
}

surface heat fluxes (see also Esau [2007]). The importance of SIC in surface energy balance has motivated several extensive in situ field experiments, such as the Surface Heat Budget of the Arctic Ocean (SHEBA) experiments [Perovich et al., 1999; Uttal et al., 2002; Persson et al., 2002], and model intercomparison studies, such as the Arctic Regional Climate Model Intercomparison Project [Curry and Lynch, 2002; Tjernstrom et al., 2005; Inoue et al., 2006].

[3] The SIC affects not only surface heat fluxes but also other dynamically important processes in the ABL such as the sea level pressure (SLP), the low-level geostrophic wind, and the near-surface wind. Dynamical adjustment process of the near-surface winds is key for understanding the feedback effect between the ice and the atmosphere. The spatial scales over which this process occurs, for example across the sea-ice margins, tend to be too small to be well resolved by climate-scale models that tend to have global coverage at the expense of using coarser resolutions. An ABL-centric modeling approach has advantages in isolating and studying the ABL response to SIC change. In this study, we use a state-of-the-art weather forecast model adapted for polar regions to investigate dynamical process in the $\mathrm{ABL}$ in response to SIC variations.

[4] We designed our experiments to examine the ABL's response to different SIC conditions. A set of nearly identical simulations with an atmospheric model for the Arctic was carried out. The simulations only differ by the SIC data sets being 
used as boundary conditions. The simulated ABL responses to three different SIC products are validated against the three historical in situ measurements of the Arctic atmosphere representing different sea-ice conditions and time periods. This study focuses only the near-surface atmospheric response to sea ice; the investigation of responses in the upper atmosphere [e.g., Inoue et al., 2006] and large-scale circulation including the energy budget and the hydrological cycle [e.g., Porter et al., 2012] will be addressed elsewhere. While the main goal of this study is to improve understanding of the Arctic ABL processes, our results also provide valuable assessments of potential differences when atmospheric models use different SIC products as their boundary conditions. Such assessments can be useful in atmospheric model intercomparison studies.

[5] There are two well-accepted dynamical explanations for $\mathrm{ABL}$ response to change in sea surface temperature (SST). Wallace et al. [1989] suggest that SST variations on the oceanic mesoscales modulate the ABL stratification. A weakened stratification over warm SST enhances downward transport of high momentum from the lower troposphere, accelerating surface wind, a phenomenon that has been widely studied in both low-latitude to midlatitude oceans [e.g., Sweet et al., 1981; Chelton et al., 2004; Seo et al., 2007a, 2007b, 2008; Small et al., 2008; O'Neill, 2012] as well as in the Arctic basin [Brown, 1981; Overland, 1985]. Aircraft measurements of two cold and very stable central Arctic cases in March 1989 [Walter and Overland, 1991], for example, showed a reduction in surface stress by a factor of 4 compared to that under climatological conditions [Overland and Colony, 1994]. Consistent with this mechanism, Chelton et al. [2004] have observed an empirical relationship that vorticity and divergence of surface winds are linearly proportional to crosswind and downwind SST gradients (see also O'Neill et al., 2003, 2005).

[6] In addition, the simple ABL model by Lindzen and Nigam [1987] suggests that SST variations cause the mean temperature and hence the thickness of the ABL to change, resulting in a higher (lower) SLP anomaly over cold (warm) waters. The resultant divergence (convergence) of low-level winds leads to the maximum wind anomalies located over the front. The momentum budget indicates a linear relationship between the convergence of wind and the Laplacian of SST, which has been observed in the vicinity of the western boundary currents [e.g., Minobe et al., 2008; Shimada and Minobe, 2011]. The relationship to the Laplacian of SST implies that, over the Arctic sea ice, narrow-scale surface temperature variations near the ice margins might affect the ABL through this mechanism. While originally proposed for the tropical atmosphere, these two mechanisms have been widely observed in the mid- to high latitudes (see review by Small et al. [2008]). As will be discussed in this study, they also hold for Arctic surface-wind variations related to the technical uncertainties in SIC estimate.

[7] The paper is organized as follows. In section 2, the model and sea-ice data sets are introduced, and experimental designs are described. This is followed in section 3 by descriptions of three historical in situ measurements of the Arctic ABL process. Section 4 focuses on the validation of the model and assesses the along-track sensitivity of the ABL to SIC uncertainties. Section 5 provides the dynamical interpretations on the basin-scale and narrow-scale response in surface wind to SIC uncertainties. A summary of the results and additional discussions are provided in section 6 .

\section{Model and Experiments}

\subsection{Model}

[8] Model simulations are made by using the Weather Research and Forecasting (WRF) mesoscale atmospheric model. The core of the WRF is the Advanced Research WRF dynamic solver [Skamarock et al., 2008], which solves the fully compressible nonhydrostatic equations on a massbased terrain-following coordinate system. The WRF model has been optimized for the polar regions and dubbed Polar WRF by the Ohio State University's Byrd Polar Research Center [Hines and Bromwich, 2008]. Polar WRF has been extensively tested for various Arctic and Antarctic surface conditions [e.g., Bromwich et al., 2009; Wilson et al., 2011, 2012; Valkonen et al., 2008; Tastula et al., 2012]. Key modifications of the WRF for the polar environment are documented in detail by Bromwich et al. [2009], including the surface layer parameterization in the Noah land surface model [Chen and Dudhia, 2001] and the latent heat of sublimation for calculating latent heat flux.

[9] The adjustment of the surface albedo in Polar WRF is based on the University of Illinois Urbana Champaign algorithm [Hines et al., 2011a], which is implemented in the Noah land surface scheme for sea ice. The albedo over the snow-covered sea ice $\left(\alpha_{\text {snow }}\right)$ and snow-free surface $\left(\alpha_{\text {ice }}\right)$ is computed diagnostically based on snow depth, surface skin temperature (TSK), and near-surface air temperature (T2). The final albedo $(\alpha)$ is obtained by averaging $\alpha_{\text {ice }}$ and $\alpha_{\text {snow }}$ weighted by fractional snow cover. The variation in sea-ice thickness is not considered in this study and is set to a uniform value of $3 \mathrm{~m}$. However, this is not a valid assumption for the newly generated thin ice in the marginal ice zones (MIZ), the impact of which on the skill of the model is discussed in section 4.3.2.

[10] Except for cloud microphysics, which are based on the WRF single-moment six-class scheme [Hong and Lim, 2006] as in Wilson et al. [2012], this study uses the same set of model physics as in Bromwich et al. [2009], who demonstrated that the selected set of parameterizations produces realistic Arctic ABL evolution and surface energy balance for the SHEBA campaign year and location (see section 3.2). Longwave and shortwave radiation transfer through the atmosphere is parameterized with the Rapid Radiation Transfer Model (RRTM, [Mlawer et al., 1997]) and the Goddard scheme [Chou and Suarez, 1999], respectively. The planetary boundary layer (PBL) is treated with the Mellor-YamadaJanjic (MYJ) scheme run with the Eta surface layer scheme based on similarity theory. The Noah land surface model is altered to accommodate the surface energy balance over sea ice [Hines and Bromwich, 2008; Bromwich et al., 2009]. While general performance of the Polar WRF would depend upon the chosen set of model physics [Hines and Bromwich, 2008], the impact of alternative physics schemes, especially those for the PBL and surface layer that are relevant to this study, appears to be minor [e.g., Bromwich et al., 2009] in light of the technical SIC uncertainties documented here.

\subsection{Experimental Setup}

[11] The Polar WRF model configured for this study uses a Polar Stereographic domain of 253 by 239 grids from approximately $65^{\circ} \mathrm{N}$ to the North Pole at a horizontal resolution of $25 \mathrm{~km}$. Vertically, there is a total of 29 terrain-following 
Model domain, September SIC and in situ data

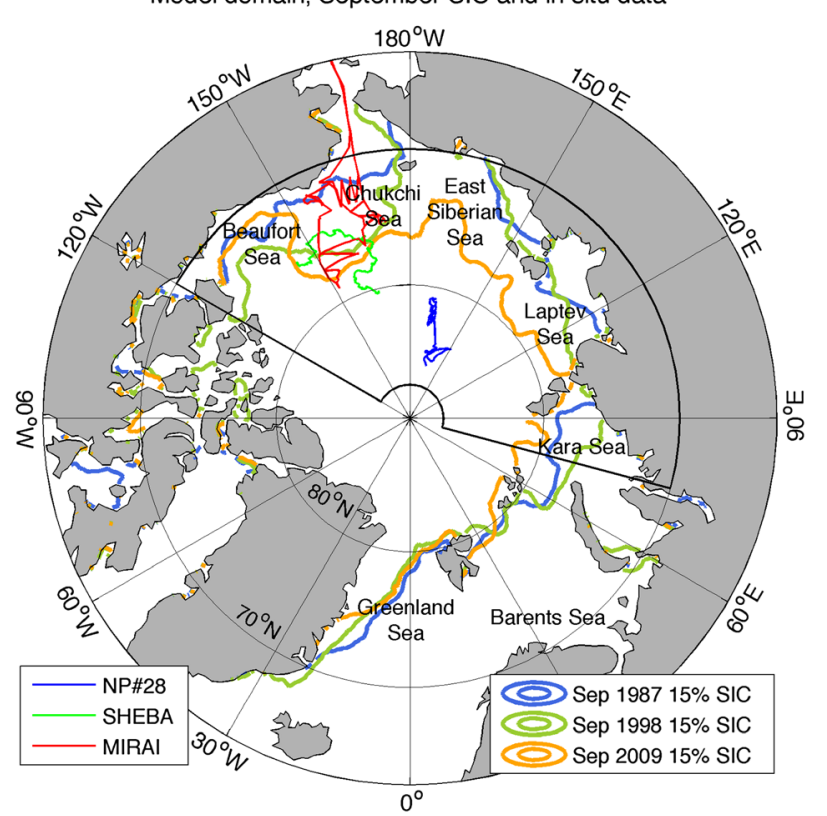

Figure 1. The geographical coverage of the Polar WRF model domain in the Arctic basin. Color shading shows the mean sea-ice concentration (SIC [\%]) averaged for September of 1987, 1998, and 2009. The three colored curves denote the tracks of the measurement stations: (red) the North Pole station 28 (NP\#28) from November 1986 to October 1987, (magenta) the SHEBA from November 1997 to October 1998 and (green) the R/V Mirai observations from 9 September to 14 October 2009. The black curves overlaid in each colored curve represent the tracks during September only for NP\#28 and SHEBA and 19-27 September 2009 for MIRAI. The green (pink) triangles denote the beginning (end) of the measurement time series. For Mirai cruise, these symbols fall outside of the domain and are not shown for display purposes. The area enclosed by the black curves is used for area-averaged statistics in this study.

sigma levels between the surface and $10 \mathrm{hPa}$, approximately 10 layers below $750 \mathrm{~m}$ height. Figure 1 shows the geographical coverage of the model domain.

[12] The Polar WRF is initialized from the European Center for Medium-Range Weather Forecasts (ECMWF) Interim reanalysis (ERA-Interim) [Dee et al., 2011] on a $0.75^{\circ}$ by $0.75^{\circ}$ grid. The 6-hourly ERA-Interim data and the daily mean sea surface temperatures (SST) are prescribed as lateral and lower boundary conditions, respectively. In this study, Polar WRF simulations are conducted, as in Bromwich et al. [2009] and Wilson et al. [2012], with a series of successive $48 \mathrm{~h}$ hindcast mode initialized daily at 0000 UTC. This allows for surface meteorological and hydrological processes to spin up during the first $24 \mathrm{~h}$. The final $24 \mathrm{~h}$ are used to produce the 12 month long time series at the 6-hourly frequency. This type of experimental setup helps maintain skillful simulations since the skill tends to be strongly dependent upon the initial condition, which should be of high quality near the observational sites of our interest. In this sense, the simulation results are rather deterministic as opposed to those with "climate mode" simulations with no successive initializations. This has advantages of eliminating the need for ensemble simulation and allowing for a clearer identification of the rapid ABL response to SIC-induced diabatic forcing. This configuration, however, may not fully capture slower adjustment process in the largescale circulation. Sensitivity of a model's skill to various hindcast lead times is left to a future study.

[13] Using this modeling setup, the Polar WRF was run for 1 year for each of the three periods that were separated by 11 years: (1) 00Z 1 November 1986 to $00 \mathrm{Z} 1$ November 1987, (2) 00Z 1 November 1997 to 00Z 1 November 1998, and (3) 00Z 1 November 2008 to 00Z 1 November 2009. These periods were chosen based on the availability of three in situ data sets. From November 1986 to October 1987, the data from the North Pole drifting buoy station \#28 over the consolidated pack ice in the central Arctic were used to validate Polar WRF. This period is called NP. The second period corresponds to the extensive field experiments from the drifting SHEBA Ice Station over the multiyear ice in the Beaufort Sea. We shall call this period SHEBA. The last period includes the 2 month expedition by the R/V Mirai in the ice-free (but near the ice edge) Beaufort Sea during September-October 2009. We call this period MIRAI.

\subsection{SIC as a Lower Boundary Forcing}

[14] Most SIC products are derived from the passive microwave imagery and are affected by such factors as errors due to atmospheric absorption and emission [Oelke, 1997] and surface roughness and emissivities of surface covered with ice and snow [Wensnahan et al., 1993; Cavalieri, 1994]. These factors are treated differently in different algorithms, leading to diverse SIC estimates in both high and low SIC conditions [Andersen et al., 2007].

[15] Polar WRF for these three periods is forced by the identical daily mean SST from ERA-Interim but with three different daily SIC data. Therefore, each period, NP, SHEBA, or MIRAI, consists of three sensitivity runs, leading up to a total of nine 1 year long Polar WRF simulations. SIC data sets used in this study are from (1) the National Aeronautics and Space Administration (NASA) TEAM algorithm [Swift and Cavalieri, 1985; Cavalieri et al., 1996], (2) the Bootstrap algorithm [Comiso, 1995, 2006], and (3) the combination of multiple algorithms by the European Organisation for the Exploitation of Meteorological Satellites (EUMET-SAT) Ocean and Sea Ice Satellite Application Facility [Tonboe et al., 2011]. These three SIC data sets are referred to as (1) NT, (2) BT, and (3) EU, respectively in this study. As discussed later in this paper, the largest gap in SIC estimates is found between NT and BT, where BT SIC is higher than NT SIC. We note that the NASA Team 2 (NT2) algorithm reduces the low SIC bias in the NT sea ice [Markus and Cavalieri, 2000, 2009], indicating that the use of NT2 sea ice would reduce the spread. As the NT2 depends on the SSMI $85 \mathrm{GHz}$ channels, however, the estimate is known to be sensitive to weather effects. NT2 also has the shorter period of record that does not cover the time period of our interest (e.g., NP). For the EU, the Bootstrap and Bristol algorithms for the Scanning Multichannel Microwave Radiometer (SSMR) and Special Sensor Microwave/Imager (SSM/I) data are used for the period of 1978-1991 and the Technical University of Denmark algorithm to the SSM/I data from 1991 onward. The NT and BT are on a $25 \mathrm{~km}$ grid, while the EU offers the SIC on a $12.5 \mathrm{~km}$ grid. SIC data prior to July 1987 are recorded every other day, not daily. For the NP runs 
Table 1. The Names of the Experiments Forced With Three SIC Data Sets for Three Different Periods

\begin{tabular}{lccc}
\hline Sea-Ice Data Set & NT (NASA Team 1 Algorithm), \\
Period & Daily $25 \mathrm{~km}$ & $\begin{array}{c}\text { BT (NASA Bootstrap Algorithm), } \\
\text { Daily 25 km }\end{array}$ & $\begin{array}{c}\text { EU (EUMET-SAT Hybrid Algorithm), } \\
\text { Daily 12.5 km }\end{array}$ \\
\hline NP: Nov. 1986 to Oct. 1987 & NP-NT & NP-BT & NP-EU \\
SHEBA: Nov. 1997 to Oct. 1998 & SHEBA-NT & SHEBA-BT & SHEBA-EU \\
MIRAI: Nov. 2008 to Oct. 2009 & MIRAI-NT & MIRAI-BT & MIRAI-EU \\
\hline
\end{tabular}

that overlap with this period (i.e., November 1986 to June 1987), the gaps are filled with a linear interpolation in time. This daily or bidaily SIC condition is held fixed in time in each of the $48 \mathrm{~h}$ integration segments, although it evolves in time from one segment to the next during the 12 month integration period [Bromwich et al., 2009]. Each run is named by a combination of the period with the used sea-ice data set. For example, the run for the SHEBA period with the NT SIC is denoted as SHEBA-NT. Table 1 summarizes the list of runs with their sea-ice conditions and the simulation periods.

[16] Figure 2 compares the annual mean SIC from these three data sets for each period in NP (top), SHEBA (middle), and MIRAI (bottom). The first column of each row shows the annual mean BT SIC, while the middle and right columns show NT-BT and EU-BT, respectively. In all periods, higher (lower) concentration and compactness in sea ice are found in BT (NT). Comiso et al. [1997] reported this difference, showing that BT gives SIC $10 \%$ higher than NT. This difference is due to the technical uncertainties present in both algorithms: the layering in the snow and thin ice types affect the normalized polarization difference in the NT algorithm, while the fluctuation in the snow and ice surface temperatures lowers the accuracy in BT. The EU SIC in all cases tends to lie between NT and BT. Figure 2 also shows the overall reduction in SIC from the NP simulation of 1986/1987 to the MIRAI simulation of 2008/2009, which relates to the negative long-term trend in Arctic sea-ice area [e.g., Cavalieri and Parkinson, 2012].

[17] SIC discrepancies are enhanced in two regions: along the periphery of the Arctic sea-ice margin and the inner pack (a) $1986 / 87 \mathrm{SIC} \mathrm{BT}$

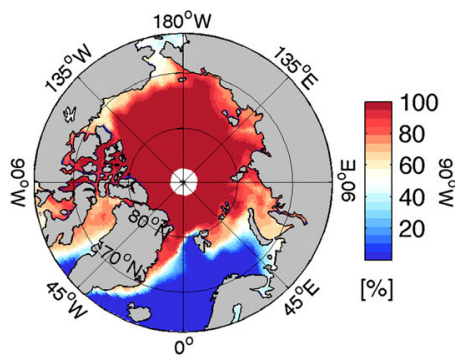

(d) $1997 / 98 \mathrm{SIC} \mathrm{BT}$

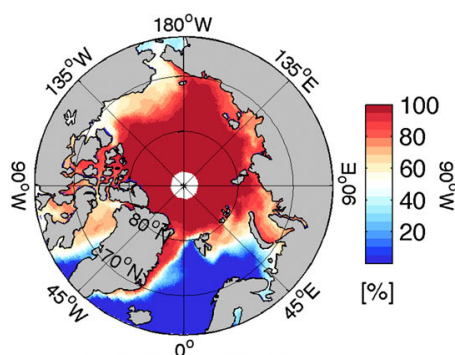

(g) $2008 / 09$ SIC BT

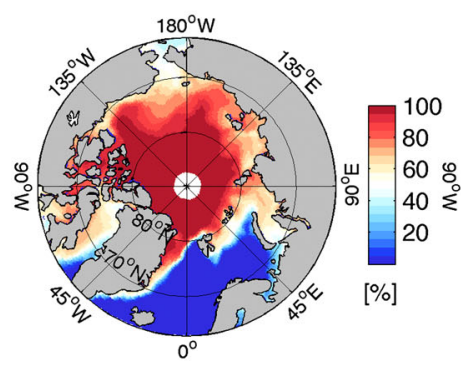

(b) $1986 / 87$ SIC NT-BT

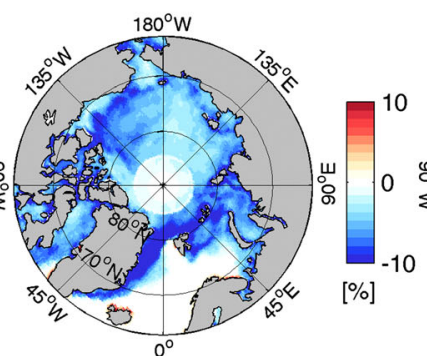

(e) $1997 / 98^{\circ} \mathrm{SIC}$ NT-BT (c) $1986 / 87$ SIC EU-BT

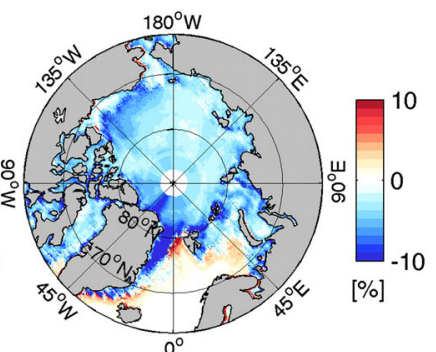

(f) $1997 / 98^{\circ} \mathrm{SIC}$ EU-BT

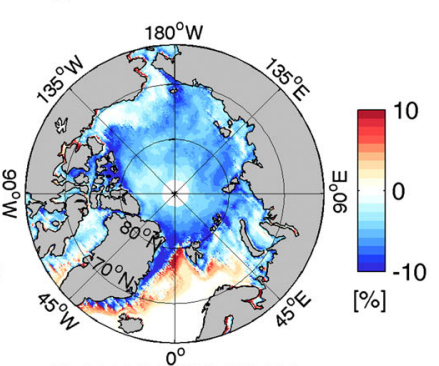

(i) $2008 / 09^{\circ} \mathrm{SIC}$ EU-BT

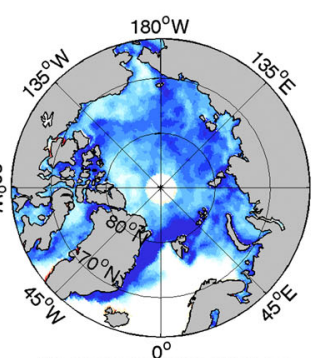

(h) $2008 / 09^{\circ} \mathrm{SIC}$ NT-BT

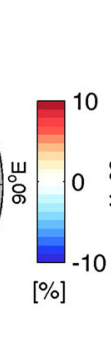

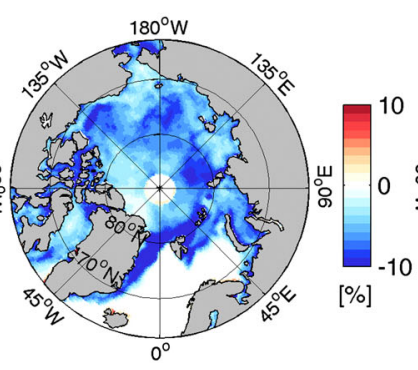

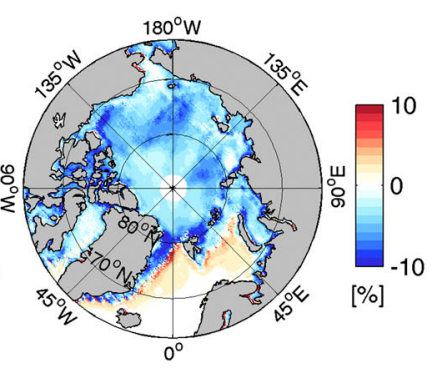

Figure 2. Three estimates of the annual mean sea-ice concentration (SIC [\%]) from (left column) the NASA Team 1 Algorithm (NT), (middle column) the NASA Bootstrap Algorithm (BT), and (right column) the EUMET-SAT Reprocessed data (EU) for the period (top row) November 1986 to October 1987 (NP period), (middle row) November 1997 to October 1998 (SHEBA period), and (bottom) November 2008 to October 2009 (MIRAI period). 
(a) SIC Std NP SON

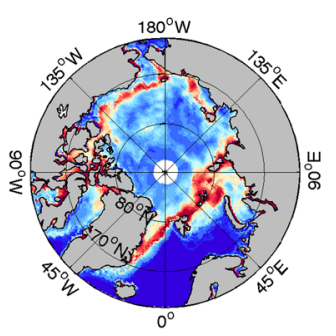

(b) SIC Std SHEBA SON

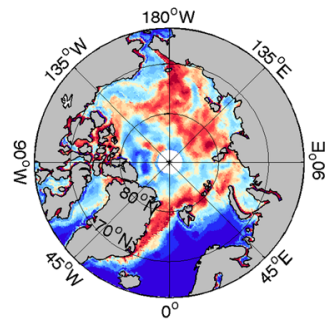

(c) SIC Std MIRAI SON

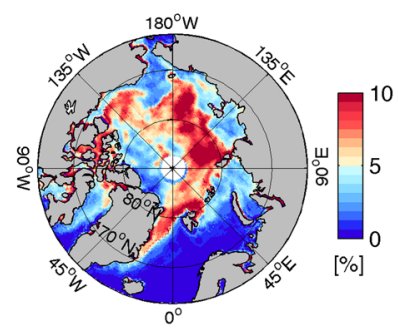

Figure 3. Across-data standard deviation (STD) of monthly mean SIC [\%] averaged for autumn (September-November) during the (a) NP, (b) SHEBA, and (c) MIRAI periods.

ice regions in the eastern and central Arctic, where the ABL response is remarkably enhanced. This becomes evident by taking the standard deviation (STD) across three SIC products (Figure 3), which is used as a measure of uncertainty. The STD was calculated across the monthly averaged SIC data sets. The autumn (September-November) STD of the SIC, for example, shows a striking uncertainty pattern with amplitudes $>10 \%$ in the central and eastern Arctic and the transpolar marginal ice regions. The uncertainties are stronger in summer and weaker in winter (figures not shown). The high uncertainties in the Fram Strait (seen year-round, not shown) could be associated with high ice variability due to large ice drift and export to the Greenland Sea and Atlantic Ocean [e.g., Vinje, 2001; Brummer et al., 2003; Kwok, 2009]. In general, the autumn uncertainties have been amplified in time from the NP period when the STD is enhanced only in the MIZ to the MIRAI period when the enhanced STD is widespread in the interior Arctic as well.

[18] When averaged over the large area of the Arctic basin from $75^{\circ} \mathrm{E}$ to $120^{\circ} \mathrm{W}$ and north of $70^{\circ} \mathrm{N}$ including the central Arctic and marginal/shelf seas, enclosed by the black line in Figure 1, a clear seasonality and trend in mean and STD emerges. Figure 4 shows the monthly averaged evolution of the across-data mean (i.e., the averages of the three SIC conditions, left axis, blue-yellow-orange) and the across-data STD (the standard deviation of the three SIC conditions, right axis, black-dark gray-light-gray). The decline in summer SIC becomes apparent from comparing the most recent period (MIRAI, orange) with the earlier periods (NP with blue and SHEBA with yellow) from July to October, during which the mean was reduced to $64 \%$ while STD is elevated to $6.8 \%$. The largest STD in NP and MIRAI occurred in July, while in SHEBA there was a broad peak in enhanced STD that lasts throughout the melting season. The agreement among the three data sets was much better during winter and spring (December-May), with the across-data mean value of $98 \%$ and STD of $1.5 \%$. Decadal trend in winter was more moderate than that in summer, which is in line with studies showing a more pronounced change of sea ice in the summer than in the winter [e.g., Comiso, 2012]. The reduction in summer SIC from the SHEBA to MIRAI period was greater than that from the NP to SHEBA period, which is also consistent with the observations that the retreat of summer sea ice in the Arctic has accelerated since 1990 [e.g., Comiso, 2012].

\section{In Situ Data for Model Validation}

[19] The following three field experiments provide in situ measurements of surface meteorology, flux, and vertical soundings. While various types of data sets are available, this study will focus on the basic near-surface meteorological variables such as surface pressure (or SLP), $2 \mathrm{~m}$ temperature (T2) and specific humidity (Q2), and $10 \mathrm{~m}$ wind speed (W10), which are commonly available from all three data sets. A more in-depth model validation focuses on the SHEBA case because this campaign provides direct observations for surface energy balance. For the purpose of model validation, we will limit our attention to periods of enhanced SIC uncertainties. The outputs are subsampled in space and time in which three in situ data exist.

\subsection{North Pole Drifting Ice Stations}

[20] The Soviet Union deployed 31 "North Pole" drifting ice stations in the Arctic Ocean from 1950 to 1991, providing in situ measurements of T2, Q2, SLP, and W10, as well as the vertical sounding from the routine radiosonde deployments [Arctic Climatology Project, 2000]. Data used here are obtained from the National Snow and Ice Data Center at http://nsidc. org/data/nsidc-0060.html, archived by Kahl et al. [1999]. The subdaily surface fields recorded from the NP station \#28 were daily averaged for the period of November 1986 to

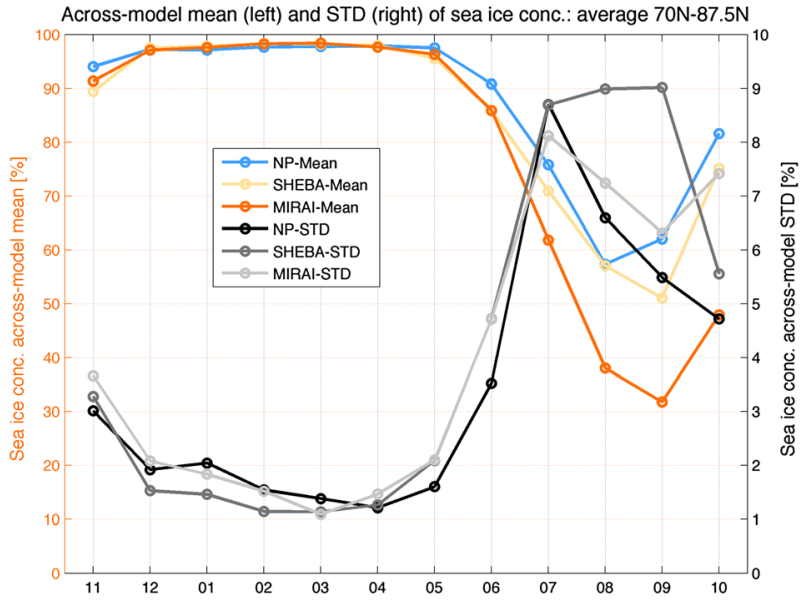

Figure 4. Monthly evolutions, averaged over the area enclosed by the black line in Figure 1b of (left axis) the across-data mean SIC ([\%], blue for NP, yellow for SHEBA, and orange for MIRAI) and (right axis) the across-data standard deviation (STD) in SIC (black for NP, dark gray for SHEBA, and light gray for MIRAI). Only the sea-ice points are used for averaging. Calculation excludes the regions of extremely high uncertainties in the Canadian Archipelagos and the Greenland and Barents Seas shown in Figure 1. 
(a) NP\#28 track

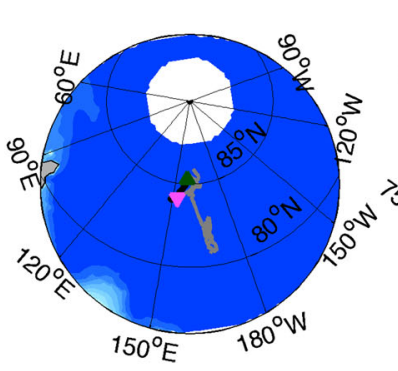

(d) NP\#28 SIC

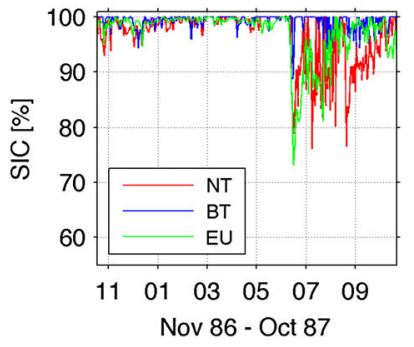

(b) SHEBA track

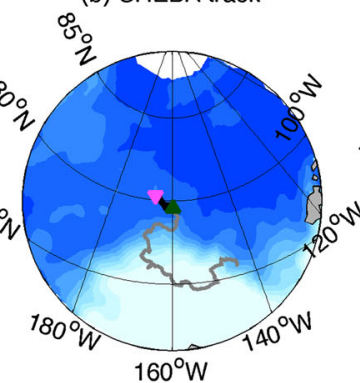

(e) SHEBA SIC

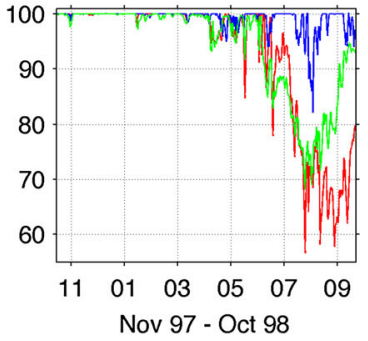

(c) MIRAI track

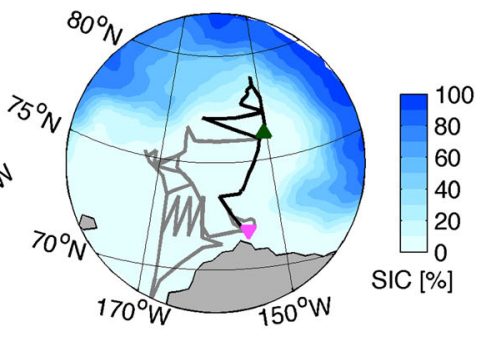

(f) MIRAI SIC

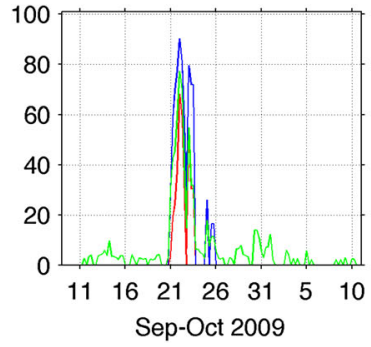

Figure 5. Time-averaged and across-data mean SIC [\%] for (a) the 1 year NP period from November 1986 to October 1987, (b) the 1 year SHEBA period from November 1997 to October 1998, and (c) the 36 day period of R/V Mirai observations from 9 September to 14 October 2009. The gray curves in each panel represent the tracks of the stations. The green (pink) triangles denote the beginning (end) of the SIC time series shown in the lower panel. For Figure 5c, these symbols fall outside of the domain and are not shown for display purposes. The black curves overlaid in gray in Figures $5 \mathrm{a}-5 \mathrm{c}$ denote the tracks during (Figure 5a) September 1987 in Figure 6, (Figure 5b) September 1998 in Figure 7, and (Figure 5c) 19-27 September 2009 in Figure 9.

October 1987. The track of the NP\#28 for this period is overlaid in Figure 5a with the September 1987 mean SIC. It represents the ABL process over the drifting pack ice.

[21] The daily along-track evolutions of NT (red), BT (blue), and EU (green) SIC are shown in Figure 5d. From November 1986 to June 1987, the SICs were above 95\% with small daily fluctuations. From the end of June, the SIC estimates begin to diverge. In June-July, both NT and EU SIC were down to $75 \%$. The NT SIC remained low until October, while the EU SIC rapidly returned to near $100 \%$ by September. In contrast, BT SIC remains persistently high year-round with only a short period of melting in early July. Given the particularly large difference in SIC estimates, validation and assessment of along-track atmospheric sensitivity will focus on the onset of freezing in September 1987 (black curve in Figure $5 \mathrm{a}-5 \mathrm{c}$ showing the track for this period).

\subsection{Ice Station SHEBA}

[22] The Surface Heat Budget of the Arctic Ocean (SHEBA) observations, conducted with a drifting station in the multiyear ice near the Beaufort Sea [Perovich et al., 1999; Uttal et al., 2002; Persson et al., 2002], provide extensive measurements of surface heat and ice mass balance from October 1997 to October 1998. Details on data calibration, processing, and uncertainty estimates were documented by Persson et al. [2002]. Temperature and humidity measurements at $2.5 \mathrm{~m}$ height are compared to those from the model at $2 \mathrm{~m}$. Hourly near-surface meteorological fields obtained from the National Center for Atmospheric Research's Earth Observing Laboratory (http:// www.eol.ucar.edu/projects/sheba) are averaged to produce 6-hourly time series, to which 6-hourly Polar WRF outputs are compared. Surface heat flux is defined positive toward the surface. The track of SHEBA Ice Station from November 1997 to October 1998 is overlaid with the September 1998 mean SIC in Figure 5b.

[23] SIC along the SHEBA trajectory (Figure 5e) is close to $100 \%$ in all three products from November 1997 through April 1998. The SIC estimates diverge as the melting begins in May-June, reaching the greatest difference in August and September. The minimum in NT SIC is in August and September, whereas the BT SIC remains above $90 \%$ even during the melting period except for a brief melting in August. The EU SIC tends to be between NT and BT during the peak melting period in August and September. Given that the SIC uncertainty is remarkably enhanced in September 1998, the subsequent validation and analysis will focus on this period.

\subsection{Arctic Cruises by the $\mathrm{R} / \mathrm{V}$ Mirai}

[24] Equipped with an ice-strengthened hull and meteorological instruments, the R/V Mirai has conducted extensive measurements of ice-free summer Arctic meteorology since 1999 [Inoue and Hori, 2011; Sato et al., 2012]. This study uses the near-surface meteorological fields from the cruise that took place in September-October 2009 [Inoue et al., 2011; http://www.godac.jamstec.go.jp/cruisedata/mirai/e/]. The gray curve in Figure 5c shows the cruise track from 9 September to 14 October 2009 overlaid with September 2009 mean SIC. The along-track SIC estimates from three data sets are shown in Figure 5f, illustrating that, during the 9 day period of 19-27 September 2009 in the Beaufort Sea ice edge (black curve in Figure 5c), the SIC peaked up 

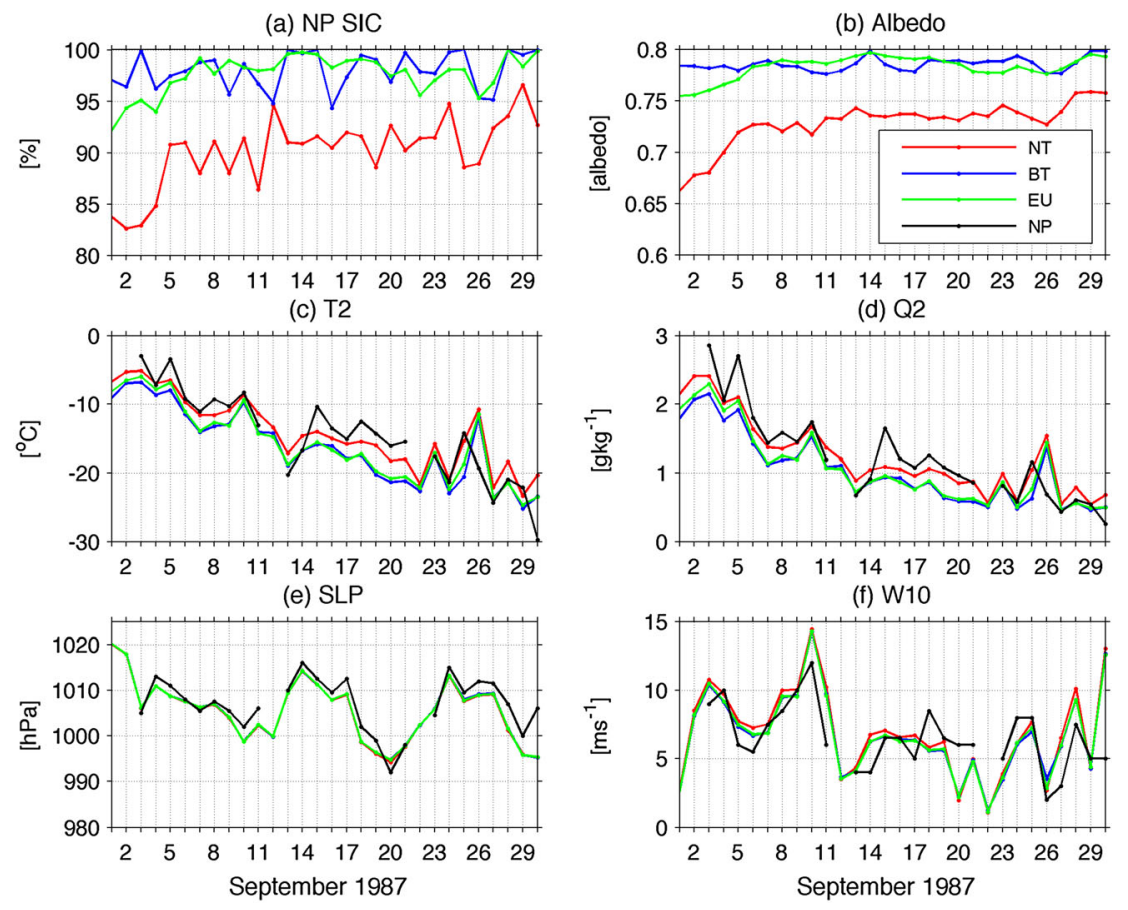

Figure 6. Daily evolutions in September 1987 of (a) three SIC estimates (\%) and (b) surface albedos, (c) $2 \mathrm{~m}$ temperatures $\left(\mathrm{T} 2,{ }^{\circ} \mathrm{C}\right),(\mathrm{d}) 2 \mathrm{~m}$ specific humidity $\left(\mathrm{Q} 2, \mathrm{~g} \mathrm{~kg}^{-1}\right)$, (e) sea-level pressure (SLP, $\mathrm{hPa}$ ), and (f) $10 \mathrm{~m}$ wind speed (W10, $\mathrm{m} \mathrm{s}^{-1}$ ) sampled following the track. The measurements are shown in black curves, while the red, blue, and green curves represent the Polar WRF result forced with NP, BT, and EU SIC, respectively. The same color-coded curves are used throughout the paper.

to $90 \%$ with large differences in daily evolution of SIC estimates. Therefore, the validation analysis will be carried out for this 9 day period.

\section{Validation and Across-Model Sensitivity}

\subsection{NP}

4.1.1. Along-Track SIC and Albedo in September 1987

[25] Figures 6a and 6b show the along-track evolutions of the prescribed SIC and the simulated surface albedo in September 1987. BT and EU SIC remain high (95\%-100\%) while NT SIC is considerably lower $(83 \%-95 \%)$. The simulated albedo reflects this difference: albedo in NT remains lower at 0.68 to 0.75 , while that in BT and EU is up to 0.8 , the maximum value in the model. With the lower SIC and albedo in NT, the ABL in NT tends to be warmer and moister than the other two cases as discussed in the next section.

\subsubsection{Bias and Across-Model Sensitivity}

[26] Figures 6c and 6f compare the daily along-track evolutions of T2, Q2, SLP, and W10 with the measurements from NP\#28 (black curves). The observed T2 displays considerable day-to-day variations with magnitude often exceeding $10^{\circ} \mathrm{C}$ [e.g., Vihma et al., 2005]. Monthly mean biases of $\mathrm{T} 2$ and Q2 in NT of $+0.31^{\circ} \mathrm{C}$ and $+0.004 \mathrm{~g} \mathrm{~kg}^{-1}$ are substantially lower and of opposite sign than those in BT $\left(-1.89^{\circ} \mathrm{C}\right.$ and $\left.-0.207 \mathrm{~g} \mathrm{~kg}^{-1}\right)$ and $\mathrm{EU}\left(-1.53^{\circ} \mathrm{C}\right.$ and $\left.-0.168 \mathrm{~g} \mathrm{~kg}^{-1}\right)$. The root mean square errors (RMSE) for T2 and Q2 are of comparable magnitude (Table 2). Thus, the result indicates that NT is the most favorable SIC condition for the simulation of T2 and Q2 during September 1988. However, the same does not hold for SLP and W10 in that the bias in NT is greater (Table 2). Furthermore, SLP and W10 show a weak across-model sensitivity despite the large SIC difference. This is a characteristic response pattern in other periods as well and is discussed further in section 5 .

\subsection{SHEBA}

4.2.1. Along-Track SIC and Albedo in September 1998 [27] Figure 7a shows that the BT SIC is near 100\% throughout September 1998, while the NT is in a lower range

Table 2. Statistics of the Polar WRF Runs Along the NP\#28 for September 1988

\begin{tabular}{|c|c|c|c|c|c|c|c|c|c|c|}
\hline & \multirow{3}{*}{$\frac{\mathrm{NP} \# 28}{\text { Mean }}$} & \multicolumn{9}{|c|}{ Individual Model Runs } \\
\hline & & \multicolumn{3}{|c|}{ NT } & \multicolumn{3}{|c|}{ BT } & \multicolumn{3}{|c|}{ EUMET } \\
\hline & & Mean & Bias & RMSE & Mean & Bias & RMSE & Mean & Bias & RMSE \\
\hline SLP $[\mathrm{hPa}]$ & 1005.9 & 1005.4 & -0.52 & 8.34 & 1005.6 & -0.38 & 8.34 & 1005.5 & -0.41 & 8.33 \\
\hline $\mathrm{T} 2\left[{ }^{\circ} \mathrm{C}\right]$ & -14.41 & -14.09 & 0.31 & 3.14 & -16.30 & -1.89 & 3.80 & -15.94 & -1.53 & 3.52 \\
\hline Q2 $\left[\mathrm{g} \mathrm{kg}^{-1}\right]$ & 1.222 & 1.225 & 0.004 & 0.32 & 1.015 & -0.207 & 0.38 & 1.053 & -0.168 & 0.36 \\
\hline $\mathrm{W} 10\left[\mathrm{~m} \mathrm{~s}^{-1}\right]$ & 6.89 & 7.23 & 0.34 & 3.39 & 6.90 & 0.01 & 3.29 & 6.91 & 0.02 & 3.28 \\
\hline
\end{tabular}


(a) SIC

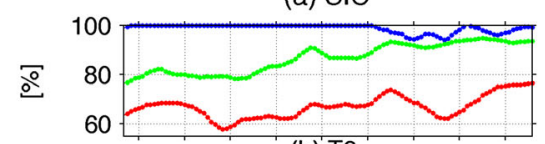

(b) T2
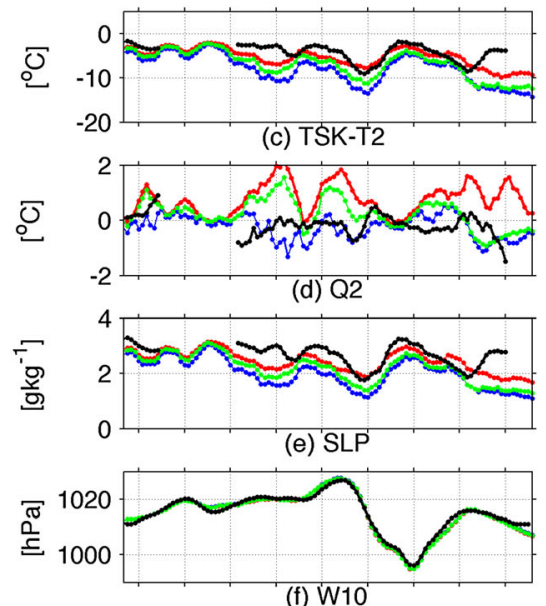

(f) $\mathrm{W} 10$

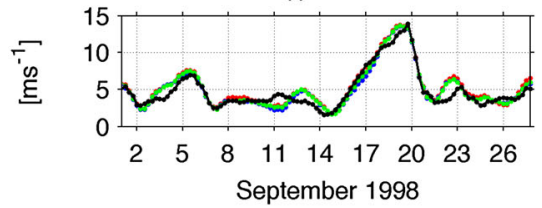

(g) Albedo

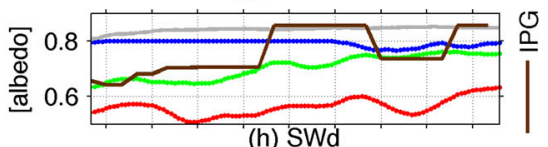

(h) SWd
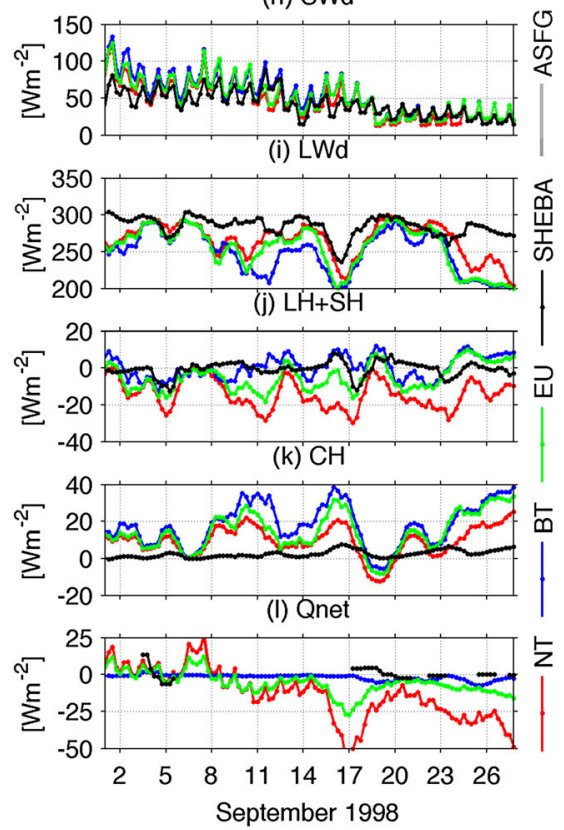

Figure 7. Six-hourly evolution of (a) SIC $[\%]$, (b) T2 $\left[{ }^{\circ} \mathrm{C}\right]$, (c) TSK-T2 $\left[{ }^{\circ} \mathrm{C}\right]$, (d) Q2 $\left[\mathrm{g} \mathrm{kg}^{-1}\right]$, (e) SLP

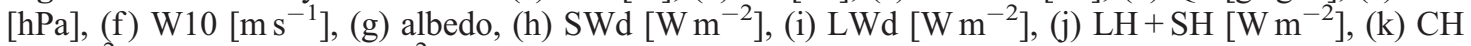
$\left[\mathrm{W} \mathrm{m}^{-2}\right]$, and (1) Qnet [ $\mathrm{W} \mathrm{m}^{-2}$ ] for September 1998 from NT (red), BT (blue), and EU (green) in comparison to the SHEBA measurements (black). The gray and brown curves in Figure $7 \mathrm{~g}$ represent the albedo measurements from the SHEBA Atmospheric Surface Flux Group (ASFG) tower (gray) and from the Ice Physics Group (IPG, brown). The flux is defined positive toward the surface and negative away from it.

between $60 \%$ and $80 \%$, similar to the NP period. The EU is about 20\% higher than NT and 20\% lower than BT during the first half of the month, which then becomes more comparable to BT during the second half. This difference is reflected in albedos, showing monthly averaged albedo of 0.79 in BT, 0.70 in EU, and 0.56 in NT. Two observed estimates of the surface albedo are available during the SHEBA period (Figure 7). One estimate from the SHEBA Atmospheric Surface Flux Group (ASFG) tower site [Persson et al., 2002] suggests the September average albedo of 0.84 (gray curve in Figure $7 \mathrm{~g}$ ), while the other from the Ice Physics Group (IPG) [Perovich et al., 2002] suggests 0.76 (brown curve). The latter measured the albedo over various surface types every $2.5 \mathrm{~m}$ along a $200 \mathrm{~m}$ survey line at least weekly from May to September 1998. In comparison to these two observed estimates, BT SIC produces a September mean albedo of 0.80 and hence the least amount of bias $(-0.04$ and +0.04 with respect to estimates from the ASFG and IPG, respectively). NT SIC, in contrast, produces too a low mean albedo (0.56) and thus the largest bias of -0.28 and -0.20 with respect to these two observed estimates. With the mean albedo of 0.70 , the bias in EU lies between the BT and NT. As discussed in the next section, however, this difference in albedo bias is not translated into the corresponding bias in ABL fields.

\subsubsection{Bias and Correlation}

[28] In the SHEBA case, the ABL parameters of all three simulations agree with the observations during most of the year except in September. September marks the onset of freezing and is thus different from other months. We focus our analysis on this special period, for which all three simulations show substantial deviations from the measurements. Figure 7 shows the time series of evolution of the near-surface atmospheric variables and the surface fluxes. The bar plots in Figure 8 and Table 3 summarize the statistics of model performance during this period. These figures show that the simulated T2 and Q2 in September 1998 are in general too cold and dry with the mean bias of $-2.7^{\circ} \mathrm{C}$ and $-0.5 \mathrm{~g} \mathrm{~kg}^{-1}$, respectively. The near-surface stability, defined as the difference between skin temperature (TSK) and T2 (TSK-T2), shows conflicting results depending upon the choice of SIC data set. NT and EU (BT) produce more unstable (stable) ABL than that in the observations. As was the case with NP, SLP (Figure 7e) and W10 (Figure 7f) do not show appreciable response considering the large spread in SIC, but they are highly consistent with the measurements.

[29] The corresponding time series of fluxes suggest that there is a positive bias of net shortwave radiation (SWnet) by $+8.7 \mathrm{~W} \mathrm{~m}^{-2}$ and net turbulent heat flux (a sum of latent heat $(\mathrm{LH})$ and sensible heat (SH) flux) of $-3.7 \mathrm{Wm}^{-2}$ (Figure 8). Conductive heat flux $(\mathrm{CH})$, calculated based on the method by Sturm et al. [1997, 2002] and Persson et al. [2002], has a positive bias of $+12 \mathrm{~W} \mathrm{~m}^{-2}$. This overestimation of $\mathrm{CH}$ (Figure $7 \mathrm{k}$ ) is likely related to the model snow depth being set to the maximum $5 \mathrm{~cm}$ over sea ice in the modified Noah land surface model [Bromwich et al., 2009], which can 

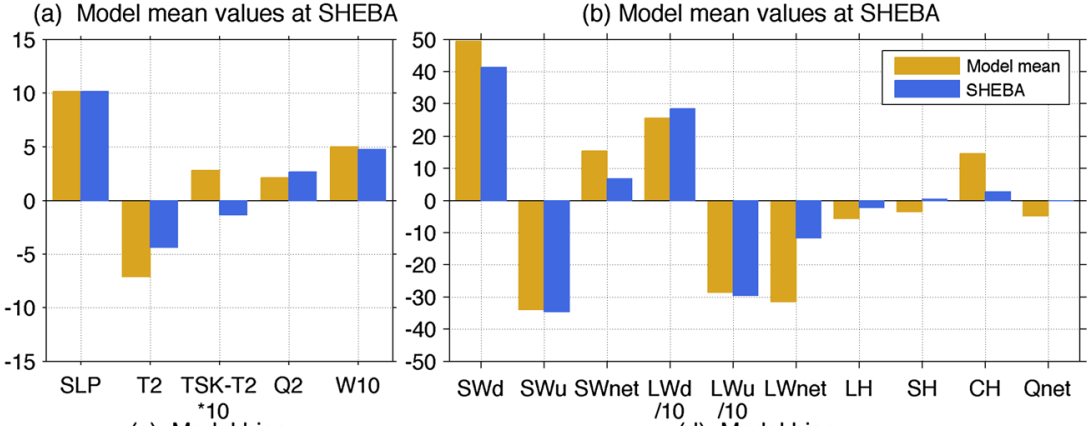

(c) Model bias

(d) Model bias
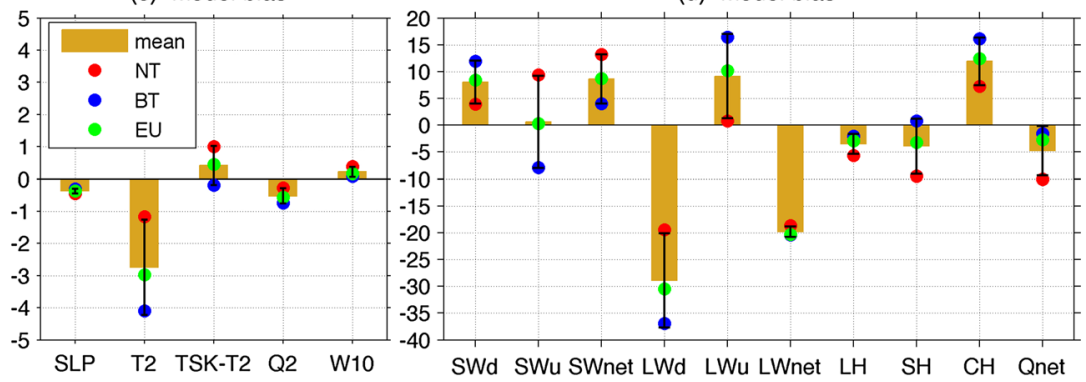

(e) Correlation: SHEBA and Model

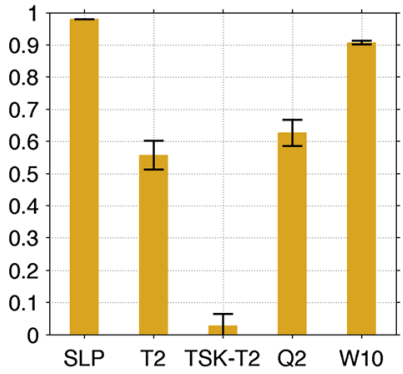

(f) Correlation: SHEBA and Model

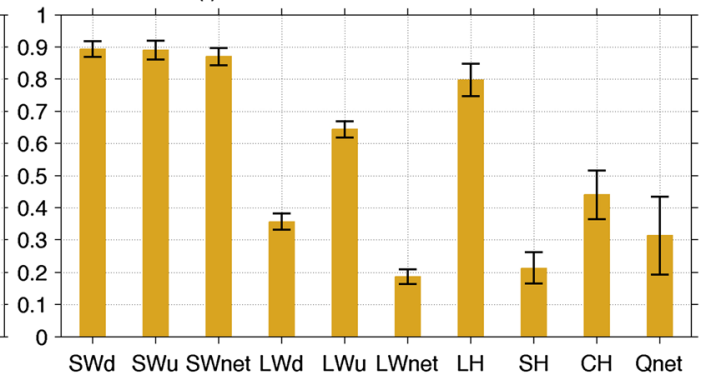

Figure 8. Bar plots for September 1998 showing (a, b) time-mean observations (blue) and the multimodel mean fields (yellow) and (c, d) the time-mean bias (across-model mean minus observations) of SLP [hPa], $\left.\mathrm{T} 2\left[{ }^{\circ} \mathrm{C}\right], \mathrm{TSK}-\mathrm{T} 2\left[{ }^{\circ} \mathrm{C}\right], \mathrm{Q} 2\left[\mathrm{~g} \mathrm{~kg}^{-1}\right], \mathrm{W} 10\left[\mathrm{~m} \mathrm{~s}^{-1}\right], \mathrm{SWd}\left[\mathrm{W} \mathrm{m}^{-2}\right], \mathrm{SWu}\left[\mathrm{W} \mathrm{m}^{-2}\right], \mathrm{LWd}^{-2} \mathrm{~W} \mathrm{~m}^{-2}\right], \mathrm{LWu}$ $\left[\mathrm{W} \mathrm{m}^{-2}\right]$, LWnet $\left[\mathrm{W} \mathrm{m}^{-2}\right], \mathrm{LH}\left[\mathrm{W} \mathrm{m}^{-2}\right], \mathrm{SH}\left[\mathrm{W} \mathrm{m}^{-2}\right], \mathrm{CH}\left[\mathrm{W} \mathrm{m}^{-2}\right]$, and Qnet [W m$\left.{ }^{-2}\right]$. The vertical scales in (Figures 8a-8d) correspond to the unit of each variable. Each dot denotes the bias of each model, where the error bars represent \pm 1 standard deviation of the bias. (e) Bar plots of correlation coefficients between across-model mean and observations, where the error bars denote \pm 1 standard deviation of the correlations. The surface heat flux is defined positive toward the surface and negative away from it. For the purpose of illustration, TSK-T2 (Figure 8a) is multiplied by 10 (i.e., the unit is $10^{-1{ }^{\circ}} \mathrm{C}$ ), while $\mathrm{LWd}$ and $\mathrm{LWu}$ (Figure $8 \mathrm{~b}$ ) are divided by 10 (thus, the unit is $10 \mathrm{~W} \mathrm{~m}^{-2}$ ).

be inconsistent to the snow stake measurements reporting snow depth up to $1 \mathrm{~m}$ at the ASFG tower [Persson et al., 2002, Figure 7].

[30] The Polar WRF also has a negative bias in net longwave radiation (LWnet) of $-20 \mathrm{~W} \mathrm{~m}^{-2}$ (Figure $8 \mathrm{~d}$ ), which is dominated by the negative bias in downward longwave radiation (LWd) of $-30 \mathrm{~W} \mathrm{~m}^{-2}$ (Figure $7 \mathrm{i}$ ) rather than a positive bias in upward longwave radiation $(\mathrm{LWu})$ of $+9 \mathrm{~W} \mathrm{~m}^{-2}$ (Figure 8d). The simulated September net heat flux (Qnet) has a negative bias of $-10 \mathrm{~W} \mathrm{~m}^{-2}$, which is dominated by the negative bias in LWd. Note, however, that the available data points for Qnet is less than $10 \%$ of the time in September (Figure 71, black curve).

\subsubsection{Across-Model Sensitivity}

[31] In September 1998, SLP and W10 have small acrossmodel spreads compared to T2, TSK-T2, and Q2 (Figures 7 and $8 \mathrm{c}$ ). This indicates a greater sensitivity of the latter fields to the local surface energy balance rather than to the large-scale circulation. The total surface energy balance varies rapidly with the ABL. Despite the larger bias in albedo discussed in section 4.2.1, NT produces the best simulated monthly mean T2 (Figure 7b) and Q2 (Figure 7d).

[32] However, EU has a much smaller SWu bias than BT and NT (Figure 8d), which reflects the superior SIC estimate by EU. BT and NT have a $10 \mathrm{~W} \mathrm{~m}^{-2}$ bias of opposing signs, which also links to the SIC estimate. The BT produces the least SWnet heating, thus producing the most realistic SWnet. In contrast, BT exhibits the largest bias in LWd and LWu, which are better simulated with NT SIC. Since the spreads in LWd and LWu cancel out, there is no significant intermodel spread in LWnet. The BT with the highest SIC is more realistic in the simulation of $\mathrm{LH}$ and $\mathrm{SH}$, although the magnitude is small during this period. The NT is more favorable for $\mathrm{CH}$, producing $10 \mathrm{~W} \mathrm{~m}^{-2}$ less bias than BT. The bias in Qnet for September 1998 is lowest (highest) with the BT (NT) SIC, where the across-model spread in Qnet is $<10 \mathrm{~W} \mathrm{~m}^{-2}$. 
Table 3. Statistics of the Polar WRF Runs Along the SHEBA for September $1988^{\text {a }}$

\begin{tabular}{|c|c|c|c|c|c|c|c|c|c|c|}
\hline & \multirow{3}{*}{$\frac{\text { SHEBA }}{\text { Mean }}$} & \multicolumn{9}{|c|}{ Individual Model Runs } \\
\hline & & \multicolumn{3}{|c|}{ NT } & \multicolumn{3}{|c|}{ BT } & \multicolumn{3}{|c|}{$\mathrm{EU}$} \\
\hline & & Mean & Bias & Correlation & Mean & Bias & Correlation & Mean & Bias & Correlation \\
\hline SLP & 1015.0 & 1014.50 & -0.45 & 0.98 & 1014.7 & -0.30 & 0.98 & 1014.6 & -0.36 & 0.98 \\
\hline $\mathrm{T} 2$ & -4.37 & -5.66 & -1.16 & 0.51 & -8.17 & -4.10 & 0.56 & -7.21 & -2.97 & 0.60 \\
\hline TSK-T2 & -0.14 & 0.86 & 1.00 & -0.00 & -0.33 & -0.19 & 0.07 & 0.31 & 0.44 & 0.01 \\
\hline Q2 & 2.66 & 2.40 & -0.26 & 0.59 & 1.92 & -0.74 & 0.62 & 2.10 & -0.56 & 0.67 \\
\hline W10 & 4.77 & 5.15 & 0.38 & 0.91 & 4.86 & 0.08 & 0.90 & 4.95 & 0.17 & 0.91 \\
\hline SWd & 41.36 & 45.24 & 3.88 & 0.87 & 53.27 & 11.91 & 0.92 & 49.75 & 8.38 & 0.89 \\
\hline $\mathrm{SWu}$ & -34.55 & -25.20 & 9.35 & 0.86 & -42.41 & -7.86 & 0.92 & -34.24 & 0.31 & 0.89 \\
\hline SWnet & 6.81 & 20.04 & 13.23 & 0.85 & 10.86 & 4.05 & 0.90 & 15.50 & 8.69 & 0.86 \\
\hline LWd & 283.55 & 264.08 & -19.48 & 0.33 & 246.67 & -36.88 & 0.36 & 253.08 & -30.47 & 0.38 \\
\hline LWu & -295.27 & -294.47 & 0.80 & 0.64 & -278.81 & 16.46 & 0.62 & -285.14 & 10.14 & 0.67 \\
\hline LWnet & -11.72 & -30.39 & -18.67 & 0.16 & -32.14 & -20.42 & 0.20 & -32.06 & -20.34 & 0.20 \\
\hline LH & -2.13 & -7.77 & -5.64 & 0.75 & -4.21 & -2.08 & 0.79 & -5.05 & -2.92 & 0.85 \\
\hline SH & 0.39 & -9.04 & -9.42 & 0.23 & 1.18 & 0.80 & 0.25 & -2.81 & -3.20 & 0.16 \\
\hline $\mathrm{CH}$ & 2.73 & 9.99 & 7.26 & 0.36 & 18.82 & 16.09 & 0.45 & 15.12 & 12.39 & 0.51 \\
\hline Qnet & -0.01 & -10.06 & -10.05 & 0.19 & -1.59 & -1.58 & 0.43 & -2.70 & -2.69 & 0.32 \\
\hline
\end{tabular}

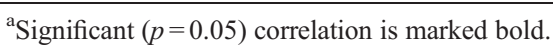

\subsection{MIRAI Cruise 2009 September-October} 4.3.1. Along-Track SIC and Albedo During 19-27 September 2009

[33] Figures $9 \mathrm{a}$ and $9 \mathrm{~b}$ show the SIC and the albedo sampled along the 2009 R/V Mirai cruise from 19 to 27 September 2009 (black curve in Figures 1 and 5c). During the 9 day period, BT has the largest SIC value that reaches as high as $90 \%$, followed by EU $77 \%$ and then by NT $68 \%$ on 22 September. The simulated albedos reflect the variations in SIC, with the highest albedo in BT and the lowest in NT during this time.

\subsubsection{Bias and Across-Model Sensitivity}

[34] The across-model mean Polar WRF simulation biases toward higher $\mathrm{T} 2\left(+0.17^{\circ} \mathrm{C}\right)$, higher Q2 $\left(+0.04 \mathrm{~g} \mathrm{~kg}^{-1}\right)$, lower SLP $(-0.73 \mathrm{hPa})$, and lower W10 $\left(-0.88 \mathrm{~m} \mathrm{~s}^{-1}\right)$. The bias in $\mathrm{T} 2$ and $\mathrm{Q} 2$ seems to originate mainly from 2 days: 20 September when the simulated T2 and Q2 were relatively higher than the measurements (Figures 9c and 9d), and 22 September when they were relatively lower. The warm/ humid bias on 20 September is accompanied by the slightly weaker high pressure (Figure 9e) and the weaker wind speed (Figure 9f), indicating a less strong cold-air advection from the high-pressure center located in the East Siberian Sea at this time (not shown, J. Inoue, personal communication). The warm/humid bias can be also attributable to the warmer SST $\left(-1.2^{\circ} \mathrm{C}\right.$ for 20 September) used in the model than the measured SST $\left(-1.3^{\circ} \mathrm{C}\right)$, which would increase the turbulent (a) Mirai SIC
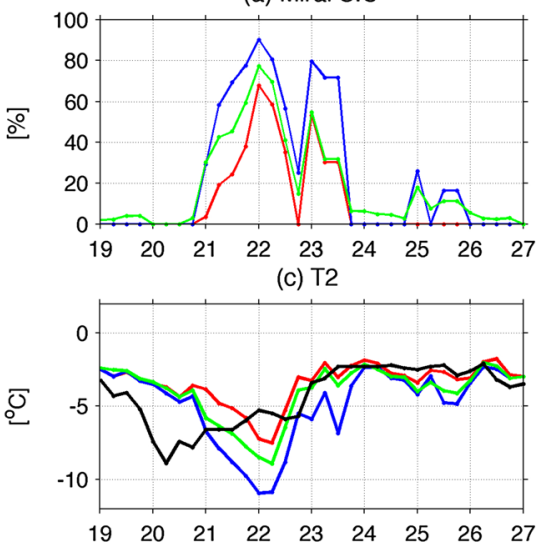

(e) SLP

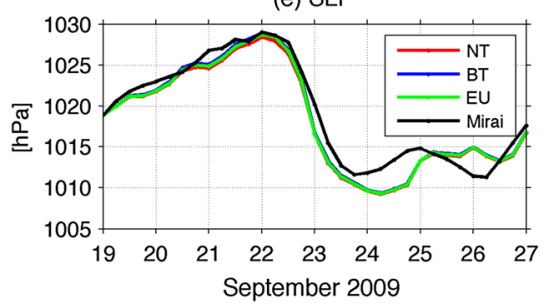

(b) Albedo
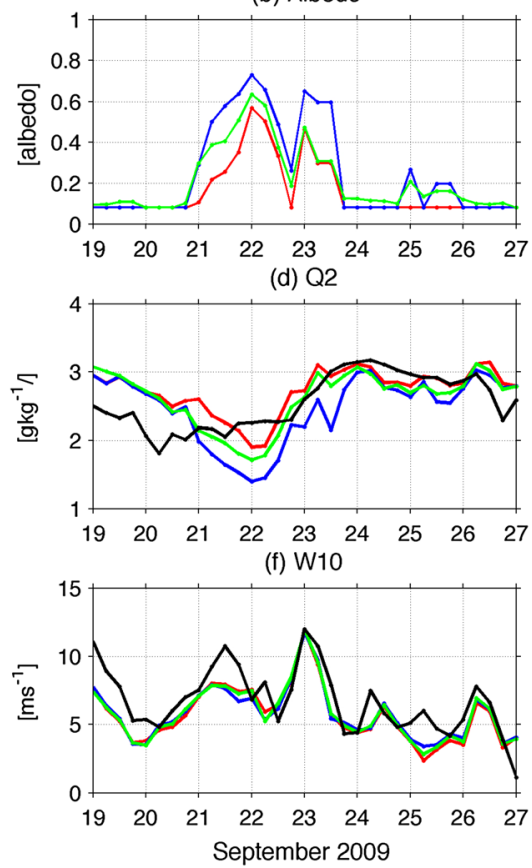

Figure 9. Six-hourly evolutions of the (a) SIC, (b) albedo, (c) T2, (d) Q2, (e) SLP, and (e) W10 from the $\mathrm{R} / \mathrm{V}$ Mirai cruise during the 9 day period of 19-27 September 2009. Tick marks in the $x$ axis denote the beginning of the date. 
Table 4. Statistics From Polar WRF Results During 19-27 September 2009 (R/V Mirai)

\begin{tabular}{|c|c|c|c|c|c|c|c|c|c|c|}
\hline & \multirow{3}{*}{$\frac{\mathrm{R} / \mathrm{V} \text { Mirai }}{\text { Mean }}$} & \multicolumn{9}{|c|}{ Individual Model Runs } \\
\hline & & \multicolumn{3}{|c|}{ NT } & \multicolumn{3}{|c|}{ BT } & \multicolumn{3}{|c|}{ EUMET } \\
\hline & & Mean & Bias & RMSE & Mean & Bias & RMSE & Mean & Bias & RMSE \\
\hline SLP $[\mathrm{hPa}]$ & 1018.9 & 1018.0 & -0.85 & 1.77 & 1018.3 & -0.61 & 1.66 & 1018.2 & -0.72 & 1.72 \\
\hline $\mathrm{T} 2\left[{ }^{\circ} \mathrm{C}\right]$ & -3.97 & -3.20 & 0.77 & 1.75 & -4.46 & -0.49 & 2.34 & -3.74 & 0.23 & 1.81 \\
\hline Q2 $\left[\mathrm{g} \mathrm{kg}^{-1}\right]$ & 2.60 & 2.79 & 0.15 & 2.81 & 2.55 & -0.08 & 2.61 & 2.68 & 0.05 & 2.71 \\
\hline $\mathrm{W} 10\left[\mathrm{~m} \mathrm{~s}^{-1}\right]$ & 6.73 & 5.79 & -0.94 & 1.69 & 5.88 & -0.84 & 1.66 & 5.88 & -0.85 & 1.67 \\
\hline
\end{tabular}

heat flux to the atmosphere. The R/V Mirai sailed through nearly ice-free waters on 20 September except for the end of the day when SIC increased (J. Inoue, personal communication), which is in general consistent with the evolution of satellite SICs (Figure 9a).

[35] On 22 September, the SIC near the R/V Mirai was almost at $100 \%$ due to extensive formation of new ice [Inoue et al., 2011], which is qualitatively consistent with the evolution of the three satellite SIC estimates exhibiting the maxima during this period. However, there exists a substantial spread in SIC estimates among the three data sets ranging from 60 to $90 \%$, which likely contributes to the bias in the model. The low skill in T2 and Q2 during this period would be also caused by the uniform ice thickness of $3 \mathrm{~m}$ prescribed as a boundary condition, which is not valid in the MIZ as observed on 22 September. Prescribing thicker ice than observed likely contributes to the latent and sensible heat flux biases, leading to the cold and dry model bias on 22 September, as seen in Figure 9.

[36] Aside from the across-model mean bias, T2 and Q2 show a relatively greater across-model spread, which corresponds to the large spread in SIC. BT (NT) produces the coldest and driest (warmest and wettest) air (Table 4). In terms of absolute magnitude of bias in T2 and Q2, EU is the best $\left(+0.25^{\circ} \mathrm{C},+0.05 \mathrm{~g} \mathrm{~kg}^{-1}\right)$, followed by BT $\left(-0.49^{\circ} \mathrm{C}\right.$, $\left.-0.08 \mathrm{~g} \mathrm{~kg}^{-1}\right)$, which is superior to NT $\left(+0.77^{\circ} \mathrm{C},+0.15 \mathrm{~g} \mathrm{~kg}^{-1}\right)$. The delayed peaks and the large across-model spread are not apparent in SLP and W10, again implying that the T2 and Q2 respond more rapidly to the SIC change. The result implies that the inaccurate representation of the SIC evolution and the thickness would have a significant impact on the skill of the weather forecast models. (a) T2 Sep,Oct,Nov

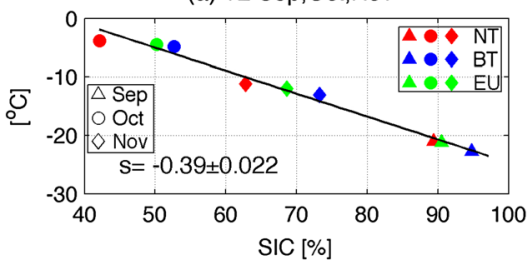

(c) TCWP Sep,Oct,Nov

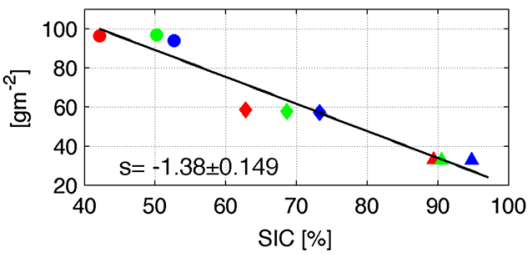

(e) SWnet Sep,Oct,Nov

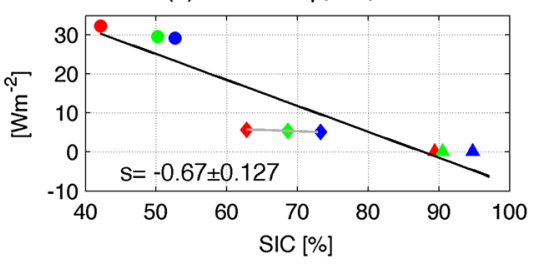

(b) TSK-T2 Sep,Oct,Nov

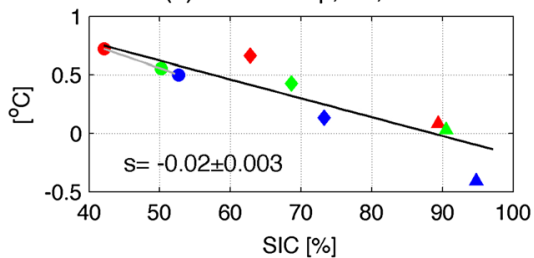

(d) SH Sep,Oct,Nov

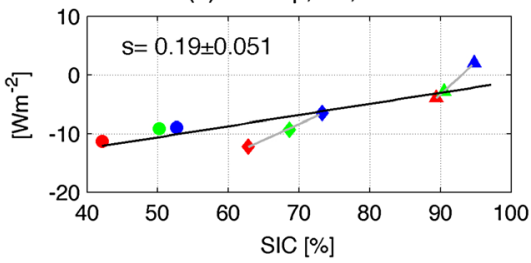

(f) LWnet Sep,Oct,Nov

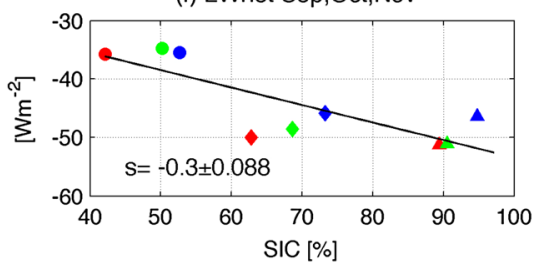

Figure 10. Scatterplots of the monthly mean ABL and surface flux fields to SIC [\%] averaged over the large area of the Arctic (Figure 1) for September-November period showing (a) T2 [ $\left.{ }^{\circ} \mathrm{C}\right]$, (b) TSK-T2 $\left[{ }^{\circ} \mathrm{C}\right]$, (c) TCWP $\left[\mathrm{g} \mathrm{m}^{-2}\right]$, (d) $\mathrm{SH}\left[\mathrm{W} \mathrm{m}^{-2}\right]$, (e) SWnet $\left[\mathrm{W} \mathrm{m}^{-2}\right]$, and (f) Qnet [W m $\left.{ }^{-2}\right]$. Dots are color coded to represent the ABL response in each month to the NT (red), BT (blue), and EU (green) SIC conditions. The scatters are overlaid with the black straight lines representing the best linear fit of the dots. Also shown in each panel are the average slope of the linear fit and the standard errors. All slopes are significant at $95 \%$ confidence level. The gray straight lines represent significant slope $(95 \%)$ of the linear fits of the response due to the technical uncertainties in SIC only estimated for each month. 
Table 5. The Slopes of Linear Fit to the Scatters Between the ABL/ Flux Fields and the SIC Uncertainties Over Large Area of the Arctic (Figure 1) and Across the Three Periods ${ }^{\mathrm{a}}$

\begin{tabular}{|c|c|c|c|c|}
\hline $\begin{array}{l}\text { Slope of } \\
\text { Linear Fit }\end{array}$ & $\begin{array}{l}\text { Spring } \\
\text { (MAM) }\end{array}$ & $\begin{array}{l}\text { Summer } \\
\text { (JJA) }\end{array}$ & $\begin{array}{c}\text { Autumn } \\
\text { (SON) }\end{array}$ & $\begin{array}{l}\text { Winter } \\
\text { (DJF) }\end{array}$ \\
\hline $\mathrm{T} 2\left[{ }^{\circ} \mathrm{C}\right]$ & -4.10 & -0.02 & -0.39 & -0.89 \\
\hline TSK-T2 $\left[{ }^{\circ} \mathrm{C}\right]$ & -0.17 & 0.00 & -0.02 & -0.14 \\
\hline PBLH [m] & -16.71 & -0.21 & -3.90 & -12.16 \\
\hline TCWP $\left[\mathrm{g} \mathrm{m}^{-2}\right]$ & -4.05 & -1.70 & -1.38 & -0.85 \\
\hline $\mathrm{LH}\left[\mathrm{W} \mathrm{m}^{-2}\right]$ & 1.40 & -0.00 & 0.14 & 0.88 \\
\hline $\mathrm{SH}\left[\mathrm{W} \mathrm{m}^{-2}\right]$ & 2.36 & -0.03 & 0.19 & 1.81 \\
\hline $\mathrm{CH}\left[\mathrm{W} \mathrm{m}^{-2}\right]$ & 4.32 & -0.05 & 0.45 & 1.58 \\
\hline $\mathrm{SWd}\left[\mathrm{W} \mathrm{m}^{-2}\right]$ & 37.76 & -3.99 & 0.58 & -0.50 \\
\hline $\mathrm{SWu}\left[\mathrm{W} \mathrm{m}{ }^{-2}\right]$ & -50.29 & 4.44 & -1.25 & 0.63 \\
\hline SWnet $\left[\mathrm{W} \mathrm{m}^{-2}\right]$ & -12.44 & 0.50 & -0.67 & 0.13 \\
\hline $\mathrm{LWd}\left[\mathrm{W} \mathrm{m}^{-2}\right]$ & -14.68 & -0.35 & -1.92 & -1.98 \\
\hline $\mathrm{LWu}\left[\mathrm{W} \mathrm{m}^{-2}\right]$ & 16.28 & 0.08 & 1.64 & 3.40 \\
\hline LWnet $\left[\mathrm{W} \mathrm{m}^{-2}\right]$ & 1.63 & -0.28 & -0.30 & 1.43 \\
\hline Qnet [W m ${ }^{-2}$ ] & -3.32 & 0.15 & -0.19 & 5.88 \\
\hline
\end{tabular}

${ }^{\text {a }}$ Significant slopes (95\%) are marked in bold. The unit is per $1 \%$ change in SIC.

MAM, March-April-May; JJA, June-July-August; SON, SeptemberOctober-November; DJF, December-January-February.

\subsection{Summary}

[37] The Polar WRF simulations provide a reasonable representation of the observed Arctic ABL, provided that the technical uncertainties in the SIC estimate remain small. The reduced skill and higher sensitivity are found with the elevated levels of SIC uncertainties during the onset of freezing in the NP and SHEBA cases and associated with the day-to-day variation in SIC near the MIZ in the MIRAI case. In addition to the effect of technical uncertainties in SIC, we have also identified that the bias in representation of large-scale circulation variability, the SST value near the sea-ice margin, and the thickness of the ice greatly influence the hindcast skills in the MIZ. In all cases, thermodynamic variables (T2 and Q2) tend to be more responsive than the dynamic variables (SLP and W10).

\section{The Pan-Arctic Response Pattern and its Seasonality}

[38] In the previous section, we explored biases of the pan-Arctic model simulation to in situ point measurements focusing on September. In this section, we use the full spatial extent of the simulations to assess the atmospheric response to the natural SIC variability (section 5.1) and the deviations resulting from the technical uncertainties

Table 6. ABL Response to the Technical Uncertainties in SIC: The Slopes of Linear Fit to the Scatters Between the ABL/Flux Fields and the SIC Uncertainties Over Large Area of the Arctic (Figure 1) in Each Month ${ }^{\mathrm{a}}$

\begin{tabular}{lccc}
\hline Slope of Linear Fit & September & October & November \\
\hline T2 $\left[{ }^{\circ} \mathrm{C}\right]$, & -0.32 & -0.08 & -0.18 \\
TSK-T2 $\left[{ }^{\circ} \mathrm{C}\right]$ & -0.10 & $-\mathbf{0 . 0 2}$ & -0.05 \\
TCWP $\left[\mathrm{g} \mathrm{m}^{-2}\right]$ & -0.05 & -0.14 & -0.12 \\
SH $\left[\mathrm{W} \mathrm{m}{ }^{-2}\right]$ & $\mathbf{1 . 1 2}$ & 0.23 & $\mathbf{0 . 5 4}$ \\
SWnet $\left[\mathrm{W} \mathrm{m}^{-2}\right]$ & -0.00 & -0.31 & $-\mathbf{0 . 0 6}$ \\
Qnet $\left[\mathrm{W} \mathrm{m}^{-2}\right]$ & 0.97 & 0.05 & 0.39 \\
\hline
\end{tabular}

${ }^{\text {a }}$ Significant slopes $(95 \%)$ are marked in bold. The unit is per $1 \%$ change in SIC. in SIC boundary conditions (section 5.2). This will help to separate different responses of the thermodynamic and dynamic variables.

\subsection{Linearity of the ABL Response to SIC and its Seasonality}

[39] Figure 10 shows the scatterplots of responses in the select ABL and flux fields to SIC for September-November periods. The ABL and SIC fields were first averaged over the large area of the Arctic (Figure 1) as well as across the three periods (NP, SHEBA, and MIRAI). The linearity of the ABL response to the range of SIC variations was then assessed by the slope $(s)$ of the linear fit (black straight lines) to the scatters of the ABL response to three different SIC products (NT, BT, and EU) for the 3 months in autumn (September, October, and November). Table 5 lists the values of $s$ for the extended list of the atmospheric and flux fields for all seasons. Hence, the linearity of the response can arise from both the natural variability in SIC (i.e., monthly evolution in SIC) and the technical uncertainties in SIC conditions (i.e., differences among NT, BT, and EU in each month). Gray lines in Figure 10 highlight ABL-SIC relationships that are solely due to technical SIC uncertainties (only significant regressions are shown). Corresponding values of slopes s are summarized in Table 6. The limited significance of linearity in the ABL response to the technical uncertainty implies that the overall linearity in the ABL response seen in Figure 10 is largely due to the natural variability in SIC boundary conditions.

[40] In autumn, the SIC values range from $40 \%$ to near $95 \%$, to which the Arctic ABL is remarkably sensitive. Per $+1 \%$ change in fall SIC, the slopes of linear fit suggest that the T2 varies by $-0.39^{\circ} \mathrm{C}$, TSK-T2 by $-0.02^{\circ} \mathrm{C}$, planetary boundary layer height $(\mathrm{PBLH})-3.9 \mathrm{~m}$, and total cloud water path (TCWP) $-1.38 \mathrm{~g} \mathrm{~m}^{-2}$, all significant at $95 \%$ confidence level (Figure 10 and Table 5). The surface fluxes also vary significantly, LH and SH by +0.14 and $+0.19 \mathrm{~W} \mathrm{~m}^{-2}$ respectively, SWnet and LWnet by -0.67 and $-0.30 \mathrm{~W} \mathrm{~m}^{-2}$ respectively, which leads to Qnet by $+0.19 \mathrm{~W} \mathrm{~m}^{-2}$ (Table 5). Since the typical across-data STD of SIC in autumn is close to $5 \%$ (Table 7), the effects of these autumn "responses" in the atmospheric field upon the ocean circulation and sea-ice variations [Hunke and Holland, 2007; Ebner et al., 2011] could be substantial.

[41] There is clearly seasonality in the sensitivity. In summer, despite the most pronounced STD of the SIC $(5.9 \%$, Table 7), weak air-sea temperature contrast limits the ABLSIC coupling, leading to generally weaker overall regression coefficients (Table 5). However, in winter and spring when the STD of SIC is only $1.3 \%$, because of the strong air-sea temperature contrast, a slight opening of sea ice can dramatically increase air temperatures [Lüpkes et al., 2008] and lower the static stability of ABL [e.g., Kay and Gettelman, 2009; Eastman and Warren, 2010]. The resultant large upward turbulent heat and moisture fluxes and increased

Table 7. The Area-Averaged (Over the Region Shown in Figure 1) Across-Data STD of SIC [\%] is Shown for Each Season

\begin{tabular}{lcccc}
\hline & $\begin{array}{c}\text { Spring } \\
\text { (MAM) }\end{array}$ & $\begin{array}{c}\text { Summer } \\
\text { (JJA) }\end{array}$ & $\begin{array}{c}\text { Autumn } \\
\text { (SON) }\end{array}$ & $\begin{array}{c}\text { Winter } \\
\text { (DJF) }\end{array}$ \\
\hline $\begin{array}{l}\text { Across-data STD } \\
\text { of SIC }\end{array}$ & 1.3 & 5.9 & 4.9 & 1.3 \\
\hline
\end{tabular}


(a) ICE NT Mean

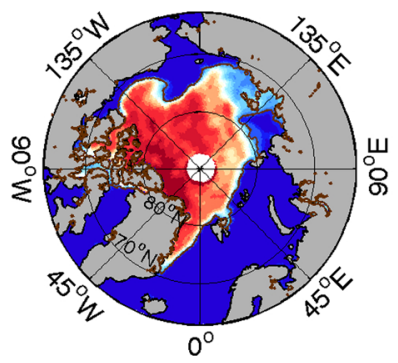

(c) T2 NT Mean

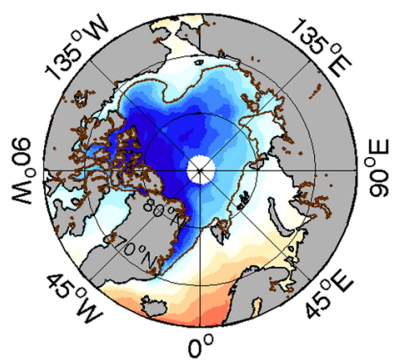

(e) PBLH NT Mean

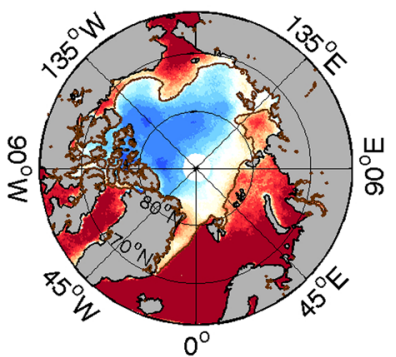

(b) ICE NT-BT

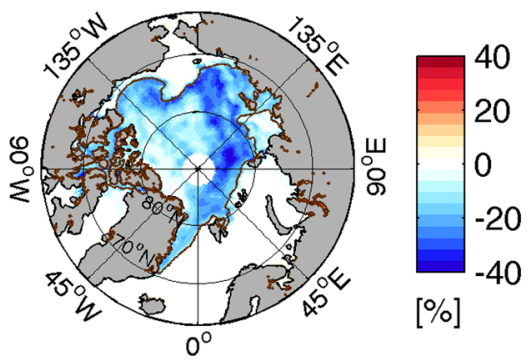

(d) T2 NT-BT

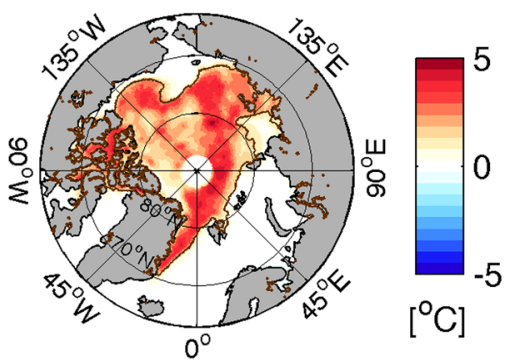

(f) PBLH NT-BT

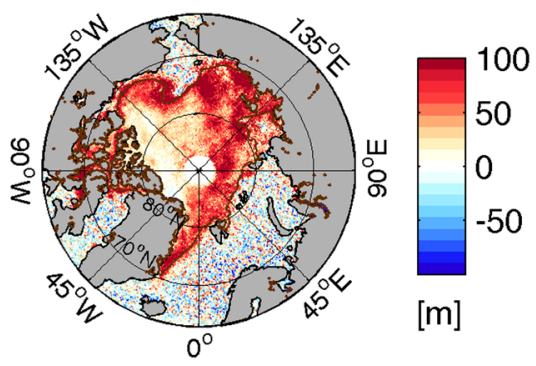

Figure 11. (left column) Monthly mean (15 September to 14 October 2009) fields in MIRAI-NT run showing (a) SIC [\%], (c) T2 [ $\left.{ }^{\circ} \mathrm{C}\right]$, and (e) the planetary boundary layer height (PBLH [m]) and (b, d, and f) their difference to BT (i.e., NT minus BT). The brown outlines in each panel denote the isolines for $15 \%$ SIC in NT.

cloudiness [e.g., Schweiger et al., 2008] yield significantly stronger coupling. As summarized in Table 5, LH and SH tend to have a greater response to SIC during the winter and spring, when $\mathrm{CH}$ also remains as an important component of the surface energy budget [Persson et al., 2002]. LWnet sensitivity is also more noticeable during the winter when it dominates the surface energy balance, while SWnet sensitivity is prominent during the summer and autumn. The simulated TCWP has higher sensitivity in summer and autumn.

[42] In autumn, the seasonal cooling of the Arctic Ocean begins while the atmosphere still remains warm, leading to the strong air-sea temperature gradient [e.g., Porter et al., 2012]. The high level of STD of SIC is maintained in the autumn (4.9\%), while the synoptic atmospheric variability remains weak, which facilitates a robust detection of the SIC-ABL process as elaborated in the following sections.

\subsection{Dynamic and Thermodynamic Response} to the Technical Uncertainties in Autumn SIC

[43] Figures $11 \mathrm{a}$ and $11 \mathrm{~b}$ show the mean and difference in SIC between NT and BT averaged for the 1 month period in autumn (15 September to 14 October 2009). We found that the SIC differences between EU and BT are very similar to those between NT and BT and thus present only results based on the latter for conciseness. The brown curves mark the isoline for $15 \%$ SIC denoting the approximate location of the sea-ice edge. The NT SIC is lower by $20-40 \%$ than the BT SIC over the pan-Arctic from the Beaufort Sea to the Kara Sea as well as in the interior Arctic. A lower SIC during autumn in NT results in a monthly mean difference in T2 that is warmer by $5^{\circ} \mathrm{C}$ in NT (Figure 11d) - a large gap considering that the monthly mean $\mathrm{T} 2$ in the NT run is about $-5^{\circ} \mathrm{C}$ (Figure 11c). This underscores that SIC uncertainty is a decisive factor for the skill of the forecast. Simmonds and Budd [1990], using an atmospheric general circulation model (AGCM), demonstrated that the Antarctic $\mathrm{T} 2$ can warm up to $6^{\circ} \mathrm{C}$ when the SIC is reduced from $100 \%$ to $50 \%$ during July to represent the ice leads. Another AGCM study based on Goddard Institute for Space Studies global climate model by Parkinson et al. [2001] reported that differences of $\pm 7 \%$ in SIC, typical accuracy of satellite SIC retrievals [Gloersen et al., 1992], can have an effect of the simulated monthly mean $\mathrm{T} 2$ by more than $6^{\circ} \mathrm{C}$ in polar regions during fall and winter. 
(a) TCWP NT Mean

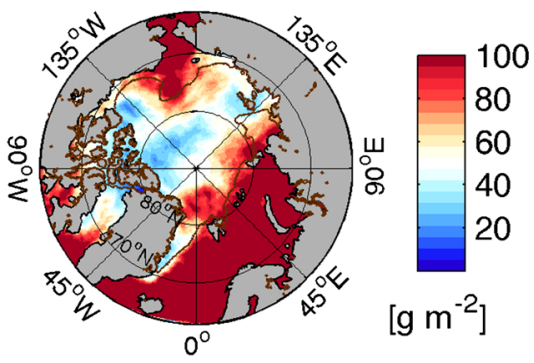

(c) W10 NT Mean

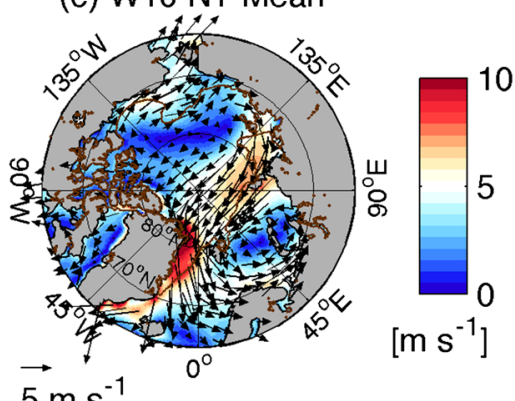

(e) Wg NT Mean

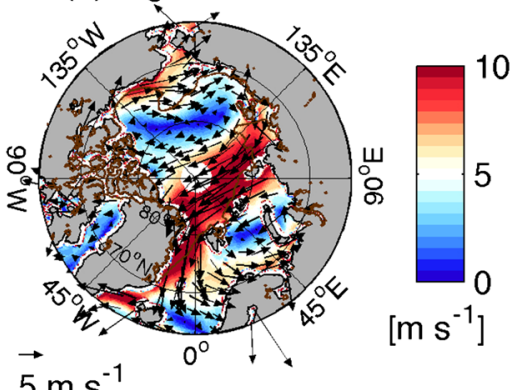

(b) TCWP NT-BT

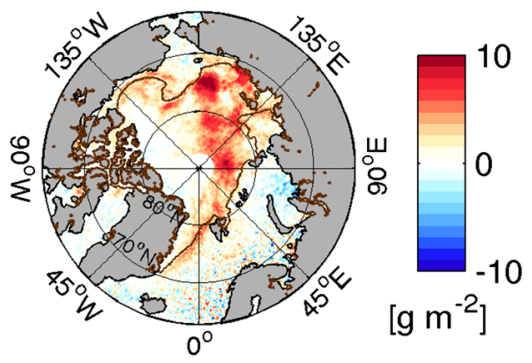

(d) W10 NT-BT

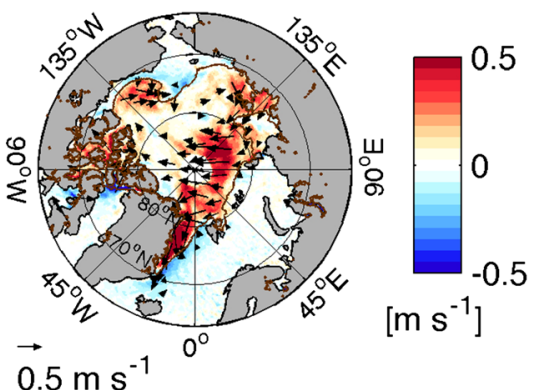

(f) Wg NT-BT

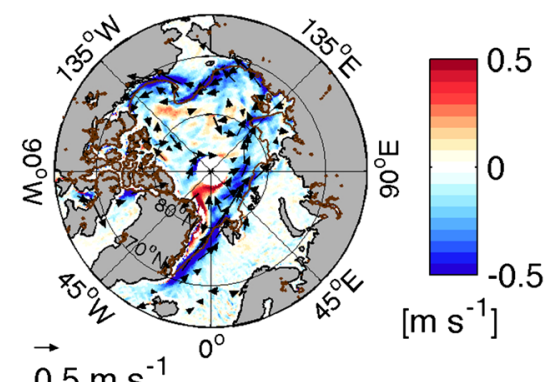

Figure 12. As in Figure 11, except for showing (top) total cloud water path (TCWP $\left[\mathrm{g} \mathrm{m}^{-2}\right]$ ), (middle) $\mathrm{W} 10\left[\mathrm{~m} \mathrm{~s}^{-1}\right]$, and (bottom) geostrophic wind $\left(\mathrm{Wg}\left[\mathrm{m} \mathrm{s}^{-1}\right]\right)$. The brown outlines in each panel denote the isolines for $15 \%$ SIC in NT.

A regional model study by Valkonen et al. [2008], applying the polar modified version of the National Center for Atmospheric Research (NCAR)/Pennsylvania State University FifthGeneration Mesoscale Model (Polar MM5) in the Weddell Sea, showed that the difference in their simulated T2 can be as large as $13^{\circ} \mathrm{C}$ during the period of the cold-air outbreak when using different SIC products.

[44] Higher T2 in NT weakens the stability of the lower atmosphere, resulting in an elevated planetary boundary layer height (PBLH) by more than $100 \mathrm{~m}$ along the periphery of the ice margin and the interior Arctic (Figure 11f). Note that the mean PBLH in this region is around $450 \mathrm{~m}$ (Figure 11e, see also Figure 13). The weakened boundary layer stability is also associated with an enhanced upward turbulent heat flux (not shown) and a significantly increased total cloud water path (TCWP, Figures 12b and 13). TCWP is the sum of cloud liquid water path and ice water path integrated from the surface to top of the atmosphere. Various satellite observations and reanalysis data indicate that an increase in cloud fraction is associated with a decrease in SIC when the boundary layer becomes unstable and upward heat flux is enhanced [e.g., Schweiger et al., 2008; Kay and Gettelman, 2009; Eastman and Warren, 2010; Palm et al., 2010]. The effect of stability adjustment within the ABL to SIC difference is further illustrated in Figure 13 showing the differences in vertical profiles. When averaged over the Arctic sea ice north of $70^{\circ} \mathrm{N}$, the destabilized lower atmosphere in NT produces the positive air temperature anomaly (blue) near the surface, which decreases with height. The PBLH is elevated by an average of $56 \mathrm{~m}$ in NT (black lines) where the most pronounced increase in cloud water path is found (green). The demonstrated sensitivity of ABL stability, surface flux, and TCWP to SIC difference is broadly consistent with the observed local thermodynamic process for cloud fraction over varied sea-ice conditions.

[45] Dynamically, an unstable ABL would be conducive to the enhanced downward transport of high momentum from the lower troposphere to the surface [Overland, 1985; Wallace et al., 1989], thus accelerating surface wind. The pronounced increase in W10 is found poleward of the ice margins (denoted by the brown outlines), whereas the reduced W10 is seen seaward. Figure $12 \mathrm{~d}$ demonstrates a $0.6 \mathrm{~m} \mathrm{~s}^{-1}$ increase in easterly W10 over a broad region within the central Arctic. Given that the monthly mean wind speed is $6 \mathrm{~m} \mathrm{~s}^{-1}$ in this region, the SIC can account for a considerable fraction of the simulated monthly mean W10 


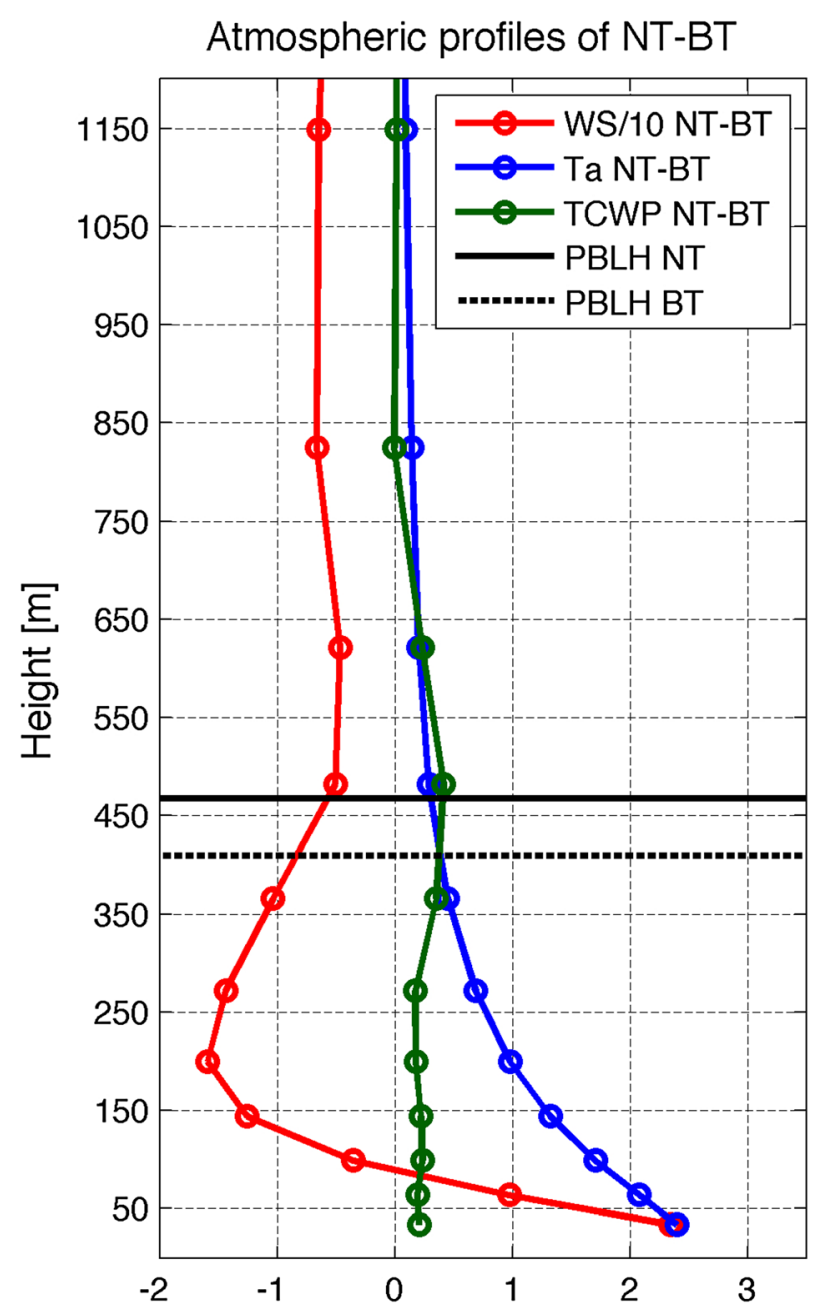

Figure 13. The Arctic-averaged (over sea-ice points north of $\left.70^{\circ} \mathrm{N}\right)$ profiles of difference $(\mathrm{NT}-\mathrm{BT})$ in wind speed (WS, red $\left.\left[10^{-1} \mathrm{~m} \mathrm{~s}^{-1}\right]\right)$, air temperature $\left(\mathrm{Ta}\right.$, blue $\left.\left[{ }^{\circ} \mathrm{C}\right]\right)$, and total cloud water path (TCWP, green $\left.\left[\mathrm{g} \mathrm{m}^{-2}\right]\right)$. Also shown are the heights of PBL in NT (black solid, $467 \mathrm{~m}$ ) and BT (black dashed, $409 \mathrm{~m}$ ). The difference in PBLH is $58 \mathrm{~m}$. The ice-covered points are defined with the SIC threshold of $15 \%$.

over the regions of the enhanced SIC uncertainties. The vertical profile of wind speed difference (Figure 13, red line) provides further evidence that weakened stability results in an accelerated wind speed below $100 \mathrm{~m}$ at the expense of a reduced wind speed aloft, indicative of the effect of downward momentum transport [Wallace et al., 1989; Small et al., 2008].

[46] In contrast, the near-surface geostrophic wind (Wg), calculated from SLP, becomes weaker with the lower SIC, the response being particularly more pronounced along the transpolar marginal ice regions (Figure 12f). Reduction in $\mathrm{Wg}$ is consistent with the change in wind profiles in Figure 13 showing the reduced wind aloft as a result of downward momentum transport. The reduction in $\mathrm{Wg}$ is $\sim-0.5 \mathrm{~m} \mathrm{~s}^{-1}$, for example, near the ice margin in the Chukchi Sea, where the mean $\mathrm{Wg}$ is about $5 \mathrm{~m} \mathrm{~s}^{-1}$. In contrast to W10, however, there is no significant change in $\mathrm{Wg}$ in the central Arctic interior to the MIZ.
[47] The contrasting responses in W10 and Wg to the SIC difference are further quantified with the binned scatterplots in Figure 14, which was calculated from the monthly averaged model outputs over the large Arctic region marked in Figure 1. The red dots in Figure 14 (top), denoting the differences in $\mathrm{W} 10$, display a quasilinear negative relationship over the range of SIC difference in all three cases (Figure 14). The slope of the linear fit that describes the wind speed as a function of SIC represents the strength of the influence of the SIC on the wind speed. This slope is similar to the coupling coefficient of Chelton et al. [2004], who used SST instead of SIC, but SIC provides a better basis in ice-covered seas than SST. Given the increasingly broader probability density functions (PDFs) of the SIC difference in time from NP period $(-20$ to $0 \%)$ toward the MIRAI period ( -35 to $0 \%$ ), it appears that $s$ becomes greater in a more recent period, for example, when comparing Figure 14e to Figure 14a. In contrast, Wg (blue dots) displays either the opposite (i.e., positive) correlation with the SIC difference in NP (Figure 14a) and MIRAI (Figure 14e) or no correlation (Figure 14c) in SHEBA when calculated over the large area over the Arctic sea ice (shown in Figure 1). We speculate that a tightening of the relationship between wind speeds and SIC over the last couple of decades as suggested by the difference between the NP and MIRAI cases is associated with the long-term trend in the Arctic sea-ice loss, which would strengthen the interaction between the SIC and the unstable ABL and hence the W10 response. Further quantification of the decadal trend in SIC-W10 relationship is, however, not possible in this study due to the insufficient sample. The strengthening of the SIC-ABL feedback in time is thus yet to be examined in more detail with a long-term continuous simulation of the Arctic ABL with a decreasing sea ice.

[48] This contrasting response in $\mathrm{W} 10$ and $\mathrm{Wg}$ is found year-round. Figure 15 shows the monthly time series of $s$ for the pan-Arctic-averaged W10 (red) and Wg (blue) to the SIC difference (NT - BT). The response of W10 is characterized by a persistent negative $s$ in all three periods, while that of $\mathrm{Wg}$ is either positive or not correlated. This marked difference in the response pattern of $\mathrm{W} 10$ and $\mathrm{Wg}$ implies that the uncertainties in SIC might have a greater impact on the area-averaged W10 rather than area-averaged $\mathrm{Wg}$.

[49] This, however, does not imply that SIC would have no impact on Wg. In fact, SLP response (Figure 16b) clearly resembles the pattern of difference in SIC (Figure 11b). Note that the Figures 16 and 17 focus on the regions near the Beaufort, Chukchi and East Siberian Seas, where this small-scale association of the wind with SIC is more pronounced. According to the marine ABL model of Lindzen and Nigam [1987], the anomalous surface temperatures generate perturbation in SLP through the hydrostatic balance, thus accelerating the surface wind across the front to converge (diverge) toward the warmer (colder) water. This divergence (convergence) of surface wind $(\nabla \cdot \vec{u})$ would then have a negative (positive) proportionality to the Laplacian of SLP $\left(\nabla^{2} P\right)$ via the relation based on momentum budget analysis, $\rho_{o}(\nabla \cdot \vec{u})=-\left(\nabla^{2} P\right) \frac{\varepsilon}{\varepsilon^{2}+f^{2}}$, where the $\vec{u}$ represents the horizontal surface-wind vectors and $\varepsilon$ the linear damping coefficients [see Minobe et al., 2008; Shimada and Minobe, 2011]. A high spatial anticorrelation 
(a) W10/Wg vs SIC: NP

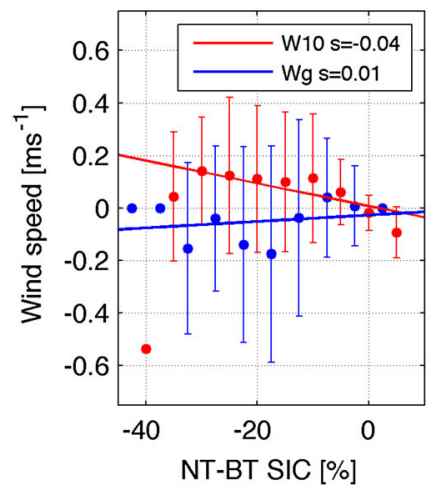

(b) PDF SIC: NP

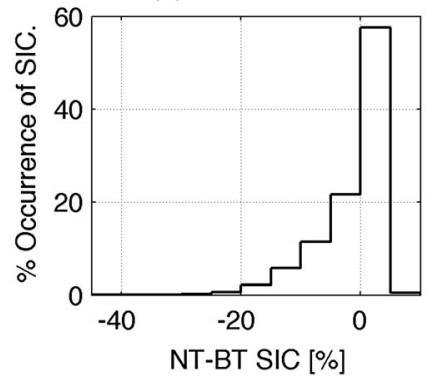

(c) W10/Wg vs SIC: SHEBA

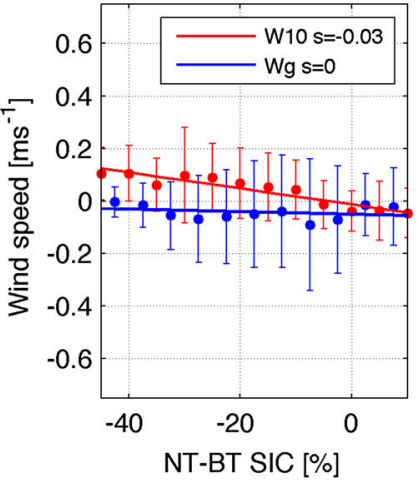

(d) PDF SIC: SHEBA

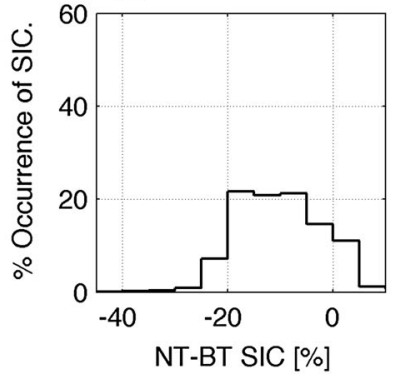

(e) W10/Wg vs SIC: MIRAI

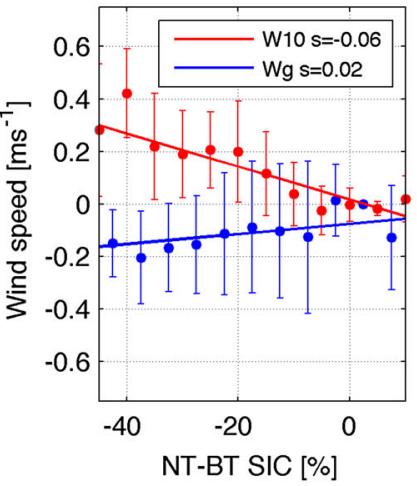

(f) PDF SIC: MIRAI

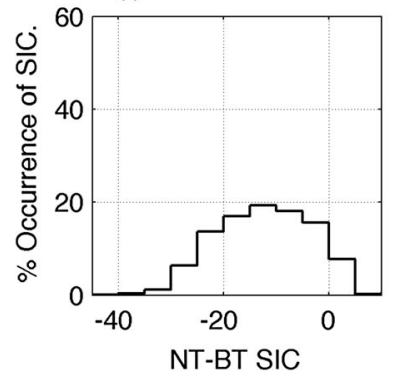

Figure 14. (top) The binned scatterplots, calculated from the monthly averaged model outputs over the large Artic region marked in Figure 1, of difference (NT - BT) of W10 (red) and Wg (blue) with respect to the difference in SIC for 15 September to 14 October in (a, b) 1987, (c, d) 1998, and (e, f) 2009. The slopes of linear fit (s) are marked in each panel with the unit of meter per second per 10\% difference in SIC. The error bars represent \pm 1 standard deviation. (bottom) The histograms of SIC difference (NT - BT). All quantities are area-averaged.

of $\nabla^{2} P$ and $\nabla \cdot \vec{u}$ as indicated by the respective fields shown in Figures 16c and 16e indicates that Lindzen and Nigam's model holds for the Arctic ABL. The vertical integration of this relationship also yields a positive linear relationship between vertical velocity, $w$ and $\nabla^{2} P$, such that $w(z)=\frac{1}{\rho_{o}}\left(\frac{\varepsilon z}{\varepsilon^{2}+f^{2}}\right) \nabla^{2} P$. Figure $17 \mathrm{a}$ shows the mean $w$ at $200 \mathrm{~m}$ height within the PBL. The narrow region of the maximum upward (downward) motions of $>0.001 \mathrm{~m} \mathrm{~s}^{-1}$ in Chukchi Sea (in Laptev Sea) is colocated with the region of positive (negative) $\nabla^{2} P$, suggestive of the important role by SLP variations across the sea ice in the vertical motions in the lower atmosphere.

[50] The same relationship holds for the difference fields. The parallel bands of positive and negative $\nabla^{2} P$ straddling the areas of large SIC difference in the Chukchi Sea (Figure 16d) correspond well to the convergence (blue) and divergence (red) of near-surface wind (Figure 16f). Though the difference in $w$ is quite noisy, the analysis nonetheless demonstrates that the anomalous upward and downward motion in the ABL across the Chukchi/Beaufort Sea ice margins (Figure 17b) is consistent with the occurrence of positive and negative difference in $\nabla^{2} P$.

[51] The narrowness in the scale of wind response in the Lindzen and Nigam's model is expected since the Laplacian of surface temperature (or SLP) is what drives the surface convergence and thus the vertical motions. As the Laplacian operator tends to more effectively emphasize smaller-scale features as in the marginal ice zones, a basin-

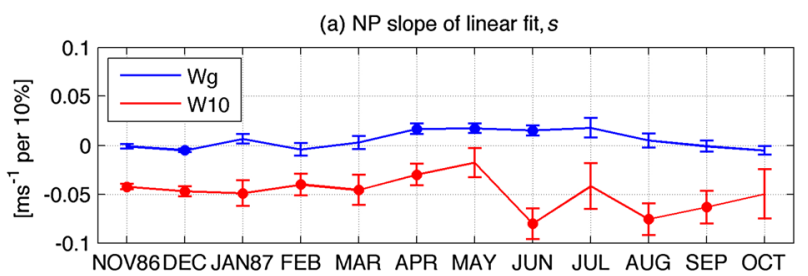

(b) SHEBA slope of lienar fit, $s$

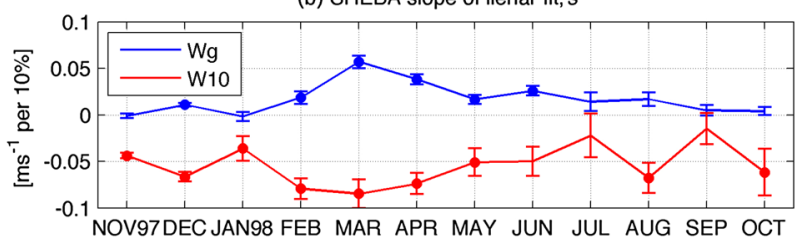

(c) MIRAI slope of lienar fit, $s$

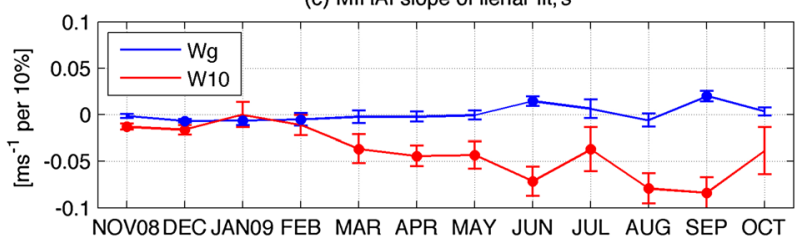

Figure 15. Monthly averaged time series of $s\left(\mathrm{~m} \mathrm{~s}^{-1}\right.$ per $10 \%$ SIC difference) for the difference (NT - BT) in W10 (blue) and $\mathrm{Wg}$ (blue) with respect to the difference in SIC during the period of (a) NP, (b) SHEBA, and (c) MIRAI. The error bars denote the standard error of the linear regression. The filled circles denote the month with the significant $(p=0.05)$ slope. 
(a) SLP NT Mean

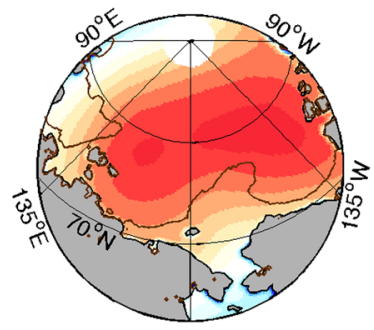

(c) $\nabla^{2}$ P NT Mean

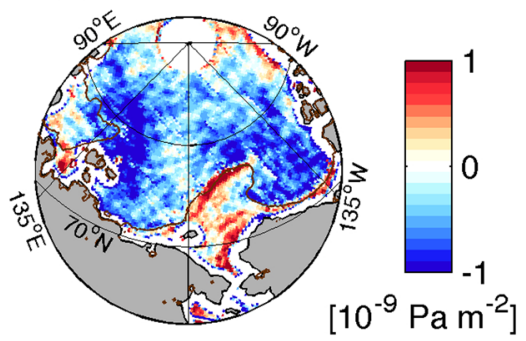

(e) Wind div/conv NT Mean

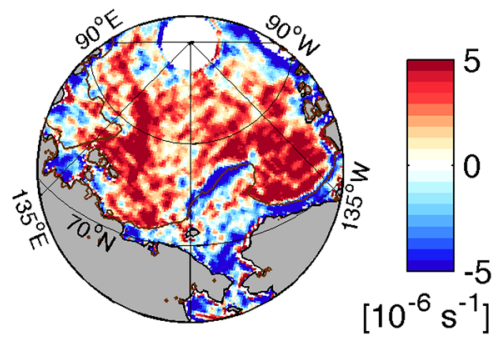

(b) SLP NT-BT

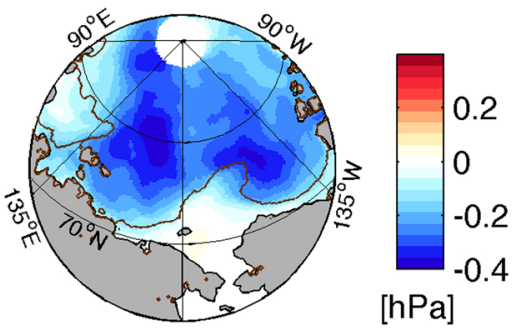

(d) $\nabla^{2}$ P NT-BT

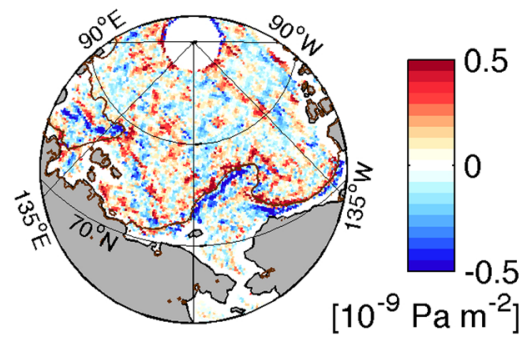

(f) Wind div/conv NT-BT

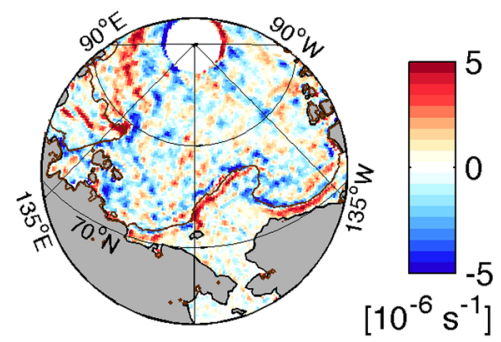

Figure 16. As in Figure 11, except for showing (a, b) sea level pressure (SLP [hPa]), (c, d) the Laplacian of SLP $\left(\nabla^{2} P\left[10^{-9} \mathrm{~Pa} \mathrm{~m}^{-2}\right]\right)$, and (e, f) the divergence of $10 \mathrm{~m}$ wind (positive for divergence and negative for convergence $\left.\left[10^{-6} \mathrm{~s}^{-1}\right]\right)$.

scale averaging used here would likely produce less obvious response due to SLP variations. This is in contrast to the process suggested by Wallace et al. [1989], where the horizontal scales of stability (response) and the SIC difference (forcing) are comparable (Figures 11-12).

[52] Due to the scarcity of surface-wind measurements over sea ice, the Arctic Ocean modeling community has often relied upon the SLP-based Wg from, for example, the International Arctic Buoy Program [Rigor, 2002], to estimate the surface stress and to drive the ocean-ice models [e.g., Proshutinsky et al., 2005, 2011; Hunke and Holland, 2007; Yang, 2009].
Our result suggests that the SLP-based wind fields may not fully represent the effect of sea-ice variations [e.g., Martin and Gerdes, 2007]. Furthermore, coarseness of horizontal resolution of atmospheric reanalysis products in the high latitudes implies that the small-scale response in $\mathrm{Wg}$ across the marginal sea ice may not be fully captured in these data sets, again a potentially important source of uncertainty in atmospheric forcing of the ocean-ice models. A more accurate representation of the near-surface-wind variability reflecting these two effects is needed to improve the predictive skills in models of ocean circulation and sea-ice variability. (a) Vertical velocity NT Mean

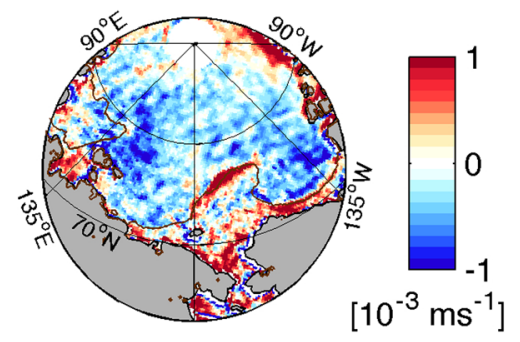

(b) Vertical velocity NT-BT

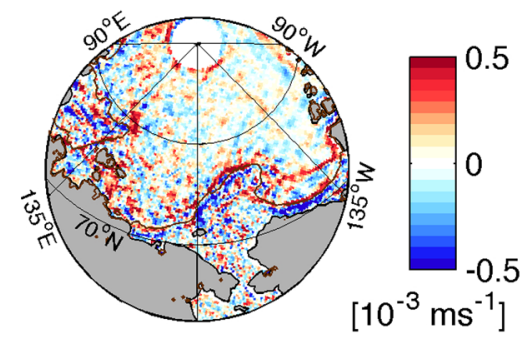

Figure 17. As in Figure 16 except for showing vertical velocity $\left(w\left[10^{-3} \mathrm{~m} \mathrm{~s}^{-1}\right]\right)$ at $200 \mathrm{~m}$ height. 


\section{Conclusion and Discussion}

[53] The most extensively and continuously observed climate variable in the Arctic is sea-ice concentration (SIC) from satellite sensors. It is imperative that we deduce potential impacts of SIC uncertainties on other climate variables that have not been well observed. In this study, we use the polaroptimized WRF (Polar WRF) model to study near-surface meteorological responses to SIC changes. Beyond uncovering the impact of technical uncertainties, our results provide a start to more insights into the dynamical and thermodynamical evolution of the Arctic atmospheric boundary layer (ABL) in relation to the ever-changing Arctic sea-ice conditions.

[54] We ran a set of three numerical experiments by only varying the underlying SIC. Three widely used SIC data sets are used in this study, the NASA/TEAM algorithm (NT), the Bootstrap algorithm (BT), and the hybrid algorithm by EUMET-SAT (EU). Difference in each sea-ice product manifests itself strongly in the long-term decadal trend [e.g., Andersen et al., 2007] and on daily to seasonal time scales [e.g., Kwok, 2002; Meier, 2005]. The spatial pattern in difference is marked in the marginal ice zone (MIZ) as well as in the inner pack ice zone of the eastern and central Arctic. The ABL response to these different SIC boundary conditions is analyzed and validated against three sets of in situ measurements.

[55] In general, Polar WRF produces skillful hindcasts of the ABL evolution provided that the SIC uncertainties are small. Much of the errors identified can be attributed to the incorrect evolution (Figures 6 and 7) and inaccurate estimates in SIC (Figure 9). The onset of freezing in September is characterized by large discrepancies in SIC and albedo, yielding varied hindcast skills. It is, however, difficult to determine conclusively which data set is the best during these periods as none of them are persistently better across the range of variables being examined. Near the MIZ, we have also identified that the bias in synoptic variability, the SST value in the model, and the misrepresentation of ice thickness significantly lower the skill in daily evolution of T2 and Q2.

[56] Over the pan-Arctic domain, one can see a clear seasonality in the $\mathrm{ABL}$ response. The $\mathrm{ABL}$ response to the variation in SIC is generally weak in summer when the technical SIC uncertainties are greatest ( $\sim \% \%$, Tables 4 and 5 ). On the other hand, a strong ABL response is found in winter when the technical uncertainties are at the minimum $(1.3 \%)$. This is closely related to seasonality of the strength of the background air-sea temperature difference, being weaker in summer and stronger in winter [e.g., Porter et al., 2012]. The sensitivity of the Arctic ABL response to the technical uncertainties in SIC can be more robustly identified in the autumn, the focus of this study, in which both the technical SIC uncertainties and the ABL response to the natural SIC variability remain substantial. The weaker synoptic variability of the Arctic atmosphere during autumn also facilitates a clearer examination of the near-surface-wind response to the uncertainties in SIC. The strength of this sensitivity shows the significant responses in nearly all the ABL and flux fields in the autumn as summarized in Table 5.

[57] On the large area of the Arctic Ocean, SIC differences affect W10 (Figure 12d), PBLH (Figure 11f), and TCWP (Figure 12b). A warmer surface results in a greater downward flux of momentum, thus locally accelerating the wind above the warmer water [Overland, 1985; Wallace et al., 1989]. Our study suggests that the lower SIC in NT results in a significant enhancement of the near-surface wind through this mechanism.

[58] Over the same broad scale, however, the geostrophic wind $(\mathrm{Wg})$ response to SIC uncertainties is not as noticeable. This may seem puzzling, as there is evidence for a coherent spatial response of sea level pressure (SLP) to SIC (Figure 16b). According to the simple ABL model of Lindzen and Nigam [1987], the wind response to surface temperature anomalies via adjustment in SLP requires that the divergence and convergence of surface wind be proportional to the Laplacian of SLP. In the monthly mean case, regions with the negative (positive) Laplacian of SLP in the eastern Arctic (East Greenland, Barents and Kara Seas) clearly correspond to those with divergence (convergence) of the surface wind (Figures 16c and 16e). This is compelling evidence that the pressure-gradient mechanism has an important influence in the Arctic. On this narrow scale, the response in wind convergence (and curl, not shown) is likely important for evolution of sea ice [e.g., Zhang et al., 2010] and the ice-edge intensified vertical motions in the atmosphere (Figures 17) and the ocean [e.g., Pickart et al., 2011].

[59] Some quantities in ABL display significant trends in response to the declining long-term SIC trends (e.g., Figure 10), which appears to be comparable to previous studies based on satellite and reanalysis data sets (not shown). However, the issue on the trends in response should be addressed with the continuous long-term model integrations resolving small-scale SIC-ABL evolutions. This is a topic of future study.

[60] The dynamic response of the atmosphere to diversities in SIC estimates, demonstrated in this study, is of great importance to the simulations of the Arctic climate system. A slight error in SIC estimates could result in a significant atmospheric response [e.g., Lüpkes et al., 2008; Valkonen et al., 2008; Ebner et al., 2011]. A seemingly minor change to the atmospheric forcing data, perhaps with comparable amplitudes to what has been discussed in this study, may generate significant differences in the Arctic ice thickness and circulations [Hunke and Holland, 2007; Ebner et al., 2011]. This two-way feedback problem should be addressed in the coupled modeling framework that allows for integrated assessment of the complex feedback process. The use of a weather forecast model with suitable representation of the observed Arctic ABL process is a good starting point. The development and testing of a fully coupled ice-ocean-atmosphere regional model is left as a future goal.

[61] Acknowledgments. The authors acknowledge the support from WHOI Arctic Research Initiative and National Science Foundation's Office of Polar Program. H.S. thanks Andrey Proshutinsky (WHOI), SangHun Park (NCAR), Keith Hines (BPRC/OSU), and Jun Inoue (JAMSTEC) for insightful comments. The authors also thank Don Perovich for providing the $200 \mathrm{~m}$ transect albedo data and the National Snow and Ice Data Center for technical assistance with handling various sea-ice data sets. Finally, the authors thank the three anonymous reviewers for their constructive comments, which helped to substantially improve the manuscript.

\section{References}

Alexander, M., U. Bhatt, J. E. Walsh, M. Timlin, J. Miller, and J. Scott (2004), The atmospheric response to realistic Arctic sea ice anomalies in an AGCM during winter, J. Clim., 17(5), 890-905.

Andersen, S., R. Tonboe, L. Kaleschke, G. Heygster, and L. T. Pedersen (2007), Intercomparison of passive microwave sea ice concentration retrievals over the high-concentration Arctic sea ice, J. Geophys. Res., 112, C08004, doi:10.1029/2006JC003543. 
Arctic Climatology Project (2000), Arctic Climatology Project-EWG Arctic Meteorology and Climate Atlas, edited by F. Fetterer and V. Radionov, National Snow and Ice Data Center, CD-ROM, Boulder, Colorado, U.S.A.

Bromwich, D. H., K. M. Hines, and L.-S. Bai (2009), Development and testing of Polar WRF: 2. Arctic Ocean, J. Geophys. Res., 114, D08122, doi:10.1029/2008JD010300.

Brown, R. A. (1981), Modeling the geostrophic drag coefficient for AIDJEX, J. Geophys. Res., 86, 1989-1994.

Brummer, B., G. Muller, and H. Hoeber (2003), A Fram Strait cyclone: Properties and impact on ice drift as measured by aircraft and buoys, J. Geophys. Res., 108(D7), 4217, doi:10.1029/2002JD002638.

Budikova, D. (2009), Role of Arctic sea ice in global atmospheric circulation: A review, Global Planet. Change, 68(3), 149-163, doi:10.1016/j. gloplacha.2009.04.001.

Budyko, M. I. (1969), The effect of solar radiation variations on the climate of the Earth, Tellus, 21, 611-619.

Cavalieri, D. J. (1994), A microwave technique for mapping thin sea ice, J. Geophys. Res., 99(C6), 12,561-12,572.

Cavalieri, D. J., and C. Parkinson (2012), Arctic sea ice variability and trends, 1979-2010, Cryosphere, 6, 881-889, doi:10.5194/tc-6-8812012.

Cavalieri, D. J., C. Parkinson, P. Gloersen, and H. J. Zwally (1996), updated yearly. Sea Ice Concentrations From Nimbus-7 SMMR and DMSP SSM/ISSMIS Passive Microwave Data, National Snow and Ice Data Center, Boulder, Colorado, U.S.A

Chelton, D. B., M. Schlax, M. H. Freilich, and R. F. Milliff (2004), Satellite measurements reveal persistent small-scale features in ocean winds, Science, 303, 978-983.

Chen, F., and J. Dudhia (2001), Coupling an advanced land-surface/ hydrology model with the Penn State/NCAR MM5 modeling system. Part I: Model implementation and sensitivity, Mon. Weather Rev., 129, 569-585.

Chou, M.-D., and M. J. Suarez (1999), A solar radiation parameterization for atmospheric studies, NASA Tech. Rep. NASA/TM-1999-10460, 15 , 38 pp., NASA Goddard Space Flight Cent., Greenbelt. Md.

Comiso, J. C. (1995), SSM/I ice concentrations using the Bootstrap algorithm, NASA Report 1380.

Comiso, J. C. (2006), SSM/I Daily and Monthly Polar Gridded Sea Ice Concentrations, May 2000, edited by J. Maslanik and J. Stroeve, National Snow and Ice Data Center, Boulder, Colo., digital media.

Comiso, J. C. (2012), Large decadal decline of the Arctic multiyear ice cover, J. Clim., 25, 1176-1193.

Comiso, J. C., D. Cavalieri, C. Parkinson, and P. Gloersen (1997), Passive microwave algorithms for sea ice concentrations: A comparison of two techniques, Remote Sens. Environ., 60, 357-384.

Curry, J. A., and A. M. Lynch (2002), Comparing Arctic regional climate models, Eos Trans. AGU, 83, 87, doi:10.1029/2002EO000051.

Dee, D. P., et al. (2011), The ERA-Interim Reanalysis: Configuration and performance of the data assimilation system, Q. J. R. Meteorol. Soc., 137, 553-597.

Deser, C., G. Magnusdottir, R. Saravanan, and A. Phillips (2004), The effects of North Atlantic SST and sea ice anomalies on the winter circulation in CCM3. Part II: Direct and indirect components of the response, J. Clim. 17(5), 877-889.

Eastman, R., and S. G. Warren (2010), Interannual variations of Arctic cloud types in relation to sea ice, J. Clim., 23, 4216-4232.

Ebner, L., D. Schroder, and G. Heinemann (2011), Impact of Laptev Sea flaw polynyas on the atmospheric boundary layer and ice production using idealized mesoscale simulations, Polar Res., 30, 7210, doi:10.3402/polar. v30i0.7210.

Esau, I. N. (2007), Amplification of turbulent exchange over wide Arctic leads: Large-eddy simulation study, J. Geophys. Res., 112, D08109, doi:10.1029/ 2006JD007225.

Gloersen, P., W. J. Campbell, D. J. Cavalieri, J. C. Comiso, C. L. Parkinson, and H. J. Zwally (1992), Arctic and Antarctic Sea Ice, 1978-1987: Satellite Passive-Microwave Observations and Analysis, pp. 290, National Aeronautics and Space Administration, Washington, D. C.

Hines, K. M., and D. H. Bromwich (2008), Development and testing of Polar WRF. Part I: Greenland Ice Sheet meteorology, Mon. Weather Rev., 136, 1971-1989.

Hines, K. M., D. H. Bromwich, L.-S. Bai, M. Barlage, and A. G. Slater (2011a), Development and testing of Polar WRF. Part III. Arctic land, J. Clim., 24, 26-48, doi:10.1175/2010JCLI3460.1.

Hines, K., D. Bromwich, A. Wilson, and D. Chapman (2011b), Sea Ice Treatment for Polar WRF. 12th Annual WRF User's Workshop. http:// www.mmm.ucar.edu/wrf/users/workshops/WS2011/Extended\%20Abstracts \%202011/P74_Hines_ExtendedAbstract_11.pdf.

Hong, S.-Y., and J.-O. Lim (2006), The WRF single-moment 6-class microphysics scheme (WSM6), J. Korean Meteor. Soc., 42(2), 129-151.
Hunke, E. C., and M. M. Holland (2007), Global atmospheric forcing data for Arctic ice-ocean modeling, J. Geophys. Res., 112, C04S14, doi:10.1029/ 2006JC003640

Inoue, J., and M. E. Hori (2011), Arctic cyclogenesis at the marginal ice zone: A contributory mechanism for the temperature amplification?, Geophys. Res. Lett., 38, L12502, doi:10.1029/2011GL047696.

Inoue, J., J. Liu, J. O. Pinto, and J. A. Curry (2006), Intercomparison of Arctic Regional Climate Models: Modeling clouds and radiation for SHEBA in May 1998, J. Clim., 19, 4167-4178.

Inoue, J., M. E. Hori, T. Enomoto, and T. Kikuchi (2011), Intercomparison of surface heat transfer near the Arctic marginal ice zone for multiple reanalyses: A case study of September 2009, SOLA, 7, 57-60.

Kahl, J. D., N. A. Zaitseva, V. Zaitseva, V. Khattatov, R. C. Schnell, D. M. Bacon, J. Bacon, V. Radionov, and M. C. Serreze (1999), Radiosonde observations from the former Soviet "North Pole" series of drifting ice stations, 1954-90, Bull. Am. Meteorol. Soc., 80, 2019-2026.

Kay, J. E., and A. Gettelman (2009), Cloud influence on and response to seasonal Arctic sea ice loss, J. Geophys. Res., 114, D18204, doi:10.1029/ 2009JD011773.

Kwok, R. (2002), Sea ice concentration estimates from satellite passive microwave radiometry and openings from SAR ice motion, Geophys. Res. Lett., 29(9), 1311, doi:10.1029/2002GL014787.

Kwok, R. (2009), Outflow of Arctic Ocean sea ice into the Greenland, and Barents Seas: 1979-2007, J. Clim., 22, 2438-2457.

Lindzen, R. S., and S. Nigam (1987), On the role of sea surface temperature gradients in forcing low-level winds and convergence in the tropics, J. Atmos. Sci., 44, 2418-2436.

Lüpkes C., V. M. Gryanik, B. Witha, M. Gryschka, S. Raasch, and T. Gollnik (2008), Modelling convection over leads with LES and a noneddy-resolving microscale model, J. Geophys. Res., 113, C09028, doi:10.1029/2007JC004099

Manabe, S., M. J. Spelman, and R. J. Stouffer (1992), Transient responses of a coupled ocean- atmosphere model to gradual changes of atmospheric CO2. Part II: Seasonal response, J. Clim., 5, 105-126.

Markus, T., and D. J. Cavalieri (2000), An enhancement of the NASA Team sea ice algorithm, IEEE Trans. Geosci. Remote Sens., 38, 1387-1398.

Markus, T., and D. J. Cavalieri (2009), The AMSR-E NT2 Sea Ice Concentration Algorithm: Its basis and implementation, J. Remote Sens. Soc. Japan., 29(1), 216-225.

Martin T., and R. Gerdes (2007), Sea ice drift variability in Arctic Ocean Model Intercomparison Project models and observations, J. Geophys. Res., 112, C04S10, doi:10.1029/2006JC003617.

Meier, W. M. (2005), Comparison of passive microwave ice concentration algorithm retrievals with AVHRR imagery in Arctic peripheral seas, IEEE Trans. Geosci. Remote Sens., 43(6), 1324-1337, doi:10.1109/ TGRS.2005.846151.

Minobe, S., A. Kuwano-Yoshida, N. Komori, S.-P. Xie, and R. J. Small (2008), Influence of the Gulf Stream on the troposphere, Nature, 452, 206-209, doi:10.1038/nature06690.

Mlawer, E. J., S. J. Taubman, P. D. Brown, M. J. Iacono, and S. A. Clough (1997), Radiative transfer for inhomogeneous atmosphere: RRTM, a validated correlated-k model for the longwave, J. Geophys. Res., 102, 16,663-16,682, doi:10.1029/97JD00237.

O'Neill, L. W. (2012), Wind speed and stability effects on coupling between surface wind stress and SST observed from buoys and satellite, J. Clim., $25,1544-1569$.

O'Neill, L. W., D. B. Chelton, and S. K. Esbensen (2003), Observations of SST-induced perturbations on the wind stress field over the Southern Ocean on seasonal timescales, J. Clim., 16, 2340-2354.

O’Neill, L. W., D. B. Chelton, S. K. Esbensen, and F. J. Wentz (2005), Highresolution satellite measurements of the atmospheric boundary layer response to SST perturbations over the Agulhas Return Current, J. Clim., 18, 2706-2723.

Oelke, C. (1997), Atmospheric signatures in sea-ice concentration estimates from passive microwaves: Modelled and observed, Int. J. Remote Sens., 18(5), 1113-1136.

Overland, J. E. (1985), Atmospheric boundary layer structure and drag coefficients over sea ice, J. Geophys. Res., 90(C5), 9029-9049.

Overland, J. E., and R. L. Colony (1994), Geostrophic drag coefficients for the central Arctic derived from Soviet drifting station data, Tellus, 46A, 75-85.

Palm, S. P., S. T. Strey, J. Spinhirne, and T. Markus (2010), Influence of Arctic sea ice extent on polar cloud fraction and vertical structure and implications for regional climate, J. Geophys. Res., 115, D21209, doi:10.1029/2010JD013900.

Parkinson, C. L., D. Rind, R. J. Healy, and D. G. Martinson (2001), The impact of sea ice concentration accuracies on climate model simulation with the GISS GCM, J. Clim., 14, 2606-2623.

Perovich, D. K., et al. (1999), Year on ice gives climate insights, Eos Trans. $A G U, 80(41), 481-486$. 


\section{SEO AND YANG: ABL RESPONSE TO SEA-ICE CONCENTRATION}

Perovich, D. K., T. C. Grenfell, B. Light, and P. V. Hobbs (2002), Seasonal evolution of the albedo of multiyear Arctic sea ice, J. Geophys. Res., 107(C10), 8044, doi:10.1029/2000JC000438

Persson, P. O. G., C. W. Fairall, E. L. Andreas, P. S. Guest, and D. K. Perovich (2002), Measurements near the Atmospheric Surface Flux Group tower at SHEBA: Near-surface conditions and surface energy budget, J. Geophys. Res., 107(C10), 8045, doi:10.1029/2000JC000705.

Pickart, R. S., M. A. Spall, G. W. K. Moore, T. J. Weingartner, R. A. Woodgate, K. Aagaard, and K. Shimada (2011), Upwelling in the Alaskan Beaufort Sea: Atmospheric forcing and local versus non-local response, Prog. Oceanogr., 88, 78-100, doi:10.1016/j.pocean.2010.11.005.

Porter, D. F., J. J. Cassano, and M. C. Serreze (2012), Local and largescale atmospheric responses to reduced Arctic sea ice and ocean warming in the WRF model, J. Geophys. Res., 117, D11115, doi:10.1029/ 2011JD016969.

Proshutinsky, A., et al. (2005), Arctic Ocean Study-Synthesis of model results and observations, Eos Trans. AGU, 86(4), 368-371.

Proshutinsky, A., et al. (2011), Recent advances in Arctic ocean studies employing models from the Arctic Ocean Model Intercomparison Project, Oceanography, 24(3), 102-113.

Rigor, I. (2002), IABP Drifting Buoy, Pressure, Temperature, Position, and Interpolated Ice Velocity, http://nsidc.org/data/g00791.html, Natl. Snow and Ice Data Cent., Boulder, Colo.

Sato, K., J. Inoue, Y.-M. Kodama, and J. E. Overland (2012), Impact of Arctic sea-ice retreat on the recent change in cloud-base height during autumn, Geophys. Res. Lett., 39, L10503, doi:10.1029/2012GL051850.

Schweiger, A. J., R. W. Lindsay, S. Vavrus, and J. A. Francis (2008), Relationships between Arctic sea ice and clouds during autumn, J. Clim., 21, 4799-4810.

Seo, H., A. J. Miller, and J. O. Roads (2007a), The Scripps Coupled OceanAtmosphere Regional (SCOAR) model, with applications in the eastern Pacific sector, J. Clim., 20, 381-402, doi:10.1175/JCLI4016.1.

Seo, H., M. Jochum, R. Murtugudde, A. J. Miller, and J. O. Roads (2007b), Feedback of tropical instability wave-induced atmospheric variability onto the ocean, J. Clim., 20, 5842-5855, doi:10.1175/JCLI4330.1.

Seo, H., R. Murtugudde, M. Jochum, and A. J. Miller (2008), Modeling of mesoscale coupled ocean-atmosphere interaction and its feedback to ocean in the Western Arabian Sea, Ocean Modell., 25, 120-131.

Shimada, T., and S. Minobe (2011), Global analysis of the pressure adjustment mechanism over sea surface temperature fronts using AIRS/Aqua data, Geophys. Res. Lett., 38, L06704, doi:10.1029/2010GL046625.

Simmonds, I., and W. F. Budd (1990), A simple parameterization of ice leads in a general circulation model, and the sensitivity of climate to change in Antarctic ice concentration, Ann. Glaciol., 14, 266-269.

Skamarock, W. C., J. B. Klemp, J. Dudhia, D. O. Gill, D. M. Barker, M. G. Duda, X. Huang, W. Wang, and J. G. Powers (2008), A description of the advanced research WRF version 3. Rep. NCAR/TN-475+STR, Natl. Cent. for Atmos. Res., Boulder, Colo.

Small, R. J., S. de Szoeke, S. P. Xie, L. O’Neill, H. Seo, Q. Song, P. Cornillon, M. Spall, and S. Minobe (2008), Air-sea interaction over ocean fronts and eddies, Dyn. Atmos. Oceans, 45, 274-319.
Sturm, M., J. Holmgren, M. König, and K. Morris (1997), The thermal conductivity of seasonal snow, J. Glaciol., 43(143), 26-42.

Sturm, M., D. K. Perovich, and J. Holmgren (2002), Thermal conductivity and heat transfer through the snow on the ice of the Beaufort Sea J. Geophys. Res., 107(C21), 8043, doi:10.1029/2000JC000409.

Sweet, W., R. Fett, J. Kerling, and P. La Violette (1981), Air-sea interaction effects in the lower troposphere across the north wall of the Gulf Stream, Mon. Weather Rev., 109, 1042-1052.

Swift, C. T., and D. J. Cavalieri (1985), Passive microwave remote sensing for sea ice research, Eos Trans. AGU, 66(49), 1210-1212.

Tastula, E.-M., T. Vihma, and E. L. Andreas (2012), Evaluation of Polar WRF from modeling the atmospheric boundary layer over Antarctic Sea ice in autumn and winter, Mon. Weather Rev., 140, 3919-3935.

Tjernstrom, M., M. Zagar, G. Svensson, J. Cassano, S. Pfeifer, A. Rinke, K. Wyser, K. Dethloff, C. Jones, and T. Semmler (2005), Modelling the Arctic boundary layer: An evaluation of six ARCMIP regional-scale models with data from the SHEBA project, Boundary Layer Meteorol., 117, 337-381, doi:10.1007/s10546-004-7954-z.

Tonboe, R., S. Eastwood, T. Lavergne, and L. T. Pedersen (2011) EUMETSAT OSI SAF Global Sea Ice Concentration Reprocessing Data, National Snow and Ice Data Center, Boulder, Colorado, U.S.A.

Uttal, T., et al. (2002), The surface heat budget of the Arctic, Bull. Am. Meteorol. Soc., 83, 255-275.

Valkonen, T., T. Vihma, and M. Doble (2008), Mesoscale modeling of the atmosphere over Antarctic sea ice: A late-autumn case study, Mon Weather Rev., 136, 1457-1474.

Vihma, T., C. Lüpkes, J. Hartmann, and H. Savijärvi (2005), Observations and modelling of cold-air advection over Arctic sea ice, Boundary Layer Meteorol., 117, 275-300.

Vinje, T. (2001), Fram Strait ice fluxes and atmospheric circulation: 1950 2000, J. Clim., 14, 3508-3517.

Wallace, J. M., T. P. Mitchell, and C. Deser (1989), The influence of sea surface temperature on surface wind in the eastern equatorial Pacific: Seasonal and interannual variability, J. Clim., 2, 1492-1499.

Walter, B. A., and J. E. Overland (1991), Aircraft observations of the mean and turbulent structure of the atmospheric boundary layer during spring in the central Arctic, J. Geophys. Res., 96(C3), 4663-4673, doi:10.1029/90JC02263.

Wensnahan, M., G. A. Maykut, T. C. Grenfell, and D. P. Winebrenne (1993), Passive microwave remote sensing of thin sea ice using principal component analysis, J. Geophys. Res., 98(C7), 12,453-12,468.

Wilson, A. B., D. H. Bromwich, and K. M. Hines (2011), Evaluation of Polar WRF forecasts on the Arctic System Reanalysis domain. Part I. Surface and upper air analysis, J. Geophys. Res., 116, D11112, doi:10.1029/ $2010 J D 015013$.

Wilson, A. B., D. H. Bromwich, and K. M. Hines (2012), Evaluation of Polar WRF forecasts on the Arctic System Reanalysis domain. 2. Atmospheric hydrologic cycle, J. Geophys. Res., 17, D04107, doi:10.1029/2011JD016765.

Yang, J. (2009), Seasonal and interannual variability of downwelling in the Beaufort Sea, J. Geophys. Res., 114, C00A14, doi:10.1029/2008JC005084.

Zhang, J., R. Woodgate, and R. Moritz (2010), Sea ice response to atmospheric and oceanic forcing in the Bering Sea, J. Phys. Oceanogr., 40(8), 1729-1747. 